\title{
Aplicação de frutas do semiárido brasileiro em produtos alimentícios à base de kefir: uma revisão sistemática
}

\author{
Application of Brazilian semiarid fruits in kefir-based food products: a systematic review
}

Aplicación de frutos semiáridos brasileños en productos alimenticios a base de kéfir: una revisión sistemática

Recebido: 26/09/2021 | Revisado: 07/10/2021 | Aceito: 13/10/2021 | Publicado: 16/10/2021

Everlândia Silva Moura Miranda

ORCID: https://orcid.org/0000-0002-2671-7005 Instituto Federal de Educação, Ciência e Tecnologia do Ceará, Brasil E-mail: everlandiamoura7@yahoo.com

Joene Vitória Rocha Santos

ORCID: https://orcid.org/0000-0001-9822-8780 Instituto Federal de Educação, Ciência e Tecnologia do Ceará, Brasil E-mail: joene_vitoria@hotmail.com

Eloi Pinheiro de Miranda

ORCID: https://orcid.org/0000-0002-9701-9634 Instituto Federal de Educação, Ciência e Tecnologia do Ceará, Brasil E-mail: eloi.miranda@ifce.edu.br

Ana Thaís Campos de Oliveira

ORCID: https://orcid.org/0000-0002-8996-6092 Instituto Federal de Educação, Ciência e Tecnologia do Ceará, Brasil

E-mail: euthaiscampos.alimentos@gmail.com

Sandra Maria Lopes dos Santos ORCID: https://orcid.org/0000-0001-9342-3931 Faculdade de Tecnologia CENTEC- Sertão Central, Brasil E-mail: anisulivan@gmail.com

Marlene Nunes Damaceno

ORCID: https://orcid.org/0000-0002-3553-6740 Instituto Federal de Educação, Ciência e Tecnologia do Ceará, Brasil E-mail: marlene@ifce.edu.br

\begin{abstract}
Resumo
O objetivo deste estudo foi compilar e analisar publicações que aplicaram frutas reconhecidas como nativas e/ou cultivadas no semiárido brasileiro no desenvolvimento de produtos obtidos a partir da fermentação dos grãos de kefir. Trata-se de uma revisão sistemática que utilizou os descritores "kefir", "fruit", "Northeastern Brazil", "semi-arid", "Caatinga biome" nas bases de dados Google Acadêmico, LILACS, Periódicos CAPES, Science Direct, SciELO e PubMed, indexados de forma isolada e associados com os operadores booleanos "and" e "or", nos idiomas português, inglês e espanhol. A busca identificou 15.017 artigos, analisados utilizando um conjunto de critérios que considerou, previamente, o título e palavras-chave, resumo, metodologia e posteriormente, a leitura integral. A revisão contemplou um total de 22 artigos que atenderam os critérios de elegibilidade, dos quais $50 \%(\mathrm{n}=11)$ estavam na língua portuguesa, sendo 27,3\% ( $\mathrm{n}=6$ ) com locus na região Nordeste. Todos os estudos selecionados apresentaram resultados entre média e alta qualidade metodológica. As frutas aplicadas foram abacaxi, açaí, banana, cacau, coco, goiaba, graviola, jabuticaba, limão, manga, mangaba, mamão e umbu, nas formas de polpa, suco, extrato, açúcar, geleia e farinha. Os estudos fazem inferências sobre as contribuições resultantes da adição das frutas nas características apresentadas nos produtos, além de apontar um elevado potencial de mercado. Dessa forma, a utilização de frutas do semiárido brasileiro em produtos fermentados de kefir é recente e progressiva, o quantitativo de estudos evidencia que sua aplicação está em expansão e que, portanto, devem ser alvo de novos estudos como alternativa promissora no mercado de alimentos potencialmente funcionais.
\end{abstract}

Palavras-chave: Alimentos funcionais; Bioma Caatinga; Fermentação; Fruto; Probióticos.

\section{Abstract}

The aim of this study was to compile and analyze publications that applied fruits recognized as native and/or cultivated in the Brazilian semiarid region in the development of products obtained from the fermentation of kefir grains. This is a systematic review that used the descriptors 'kefir', 'fruit', 'Northeastern Brazil', 'semi-arid', 'Caatinga biome' in the databases Google Scholar, LILACS, CAPES Periodicals Portal, Science Direct, SciELO and PubMed, indexed in isolation and associated with Boolean operators 'and' and 'or', in Portuguese, English and 
Spanish languages. The search identified 15.017 articles analyzed using a set of criteria that previously considered the title and keywords, abstract, methodology and later, the full reading. The review included a total of 22 articles that met the eligibility criteria, of which $50 \%(n=11)$ were in Portuguese, and $27.3 \%(n=6)$ with locus in the Northeast region. All selected studies presented results between medium and high methodological quality. The fruits applied were pineapple, açaí, banana, cocoa, coconut, guava, soursop, jabuticaba, lemon, mango, mangaba, papaya and umbu, in the form of pulp, juice, extract, sugar, jam and flour. The studies make inferences about the contributions resulting from the addition of fruits in the characteristics presented in the products, besides pointing out a high market potential. Thus, the use of Brazilian semiarid fruits in fermented kefir products is recent and progressive, the number of studies shows that its application is expanding and, therefore, should be the target of new studies as a promising alternative in the food market potentially functional.

Keywords: Functional foods; Caatinga Biome; Fermentation; Fruit; Probiotics.

\section{Resumen}

El objetivo de este estudio fue recopilar y analizar publicaciones que aplicaron frutos reconocidos como nativos y/o cultivados en el semiárido brasileño en el desarrollo de productos obtenidos de la fermentación de granos de kéfir. Se trata de una revisión sistemática que utilizó los descriptores 'kéfir', 'fruta', 'Nordeste de Brasil', 'semiárido', 'Bioma de Caatinga' en las bases de datos Google Scholar, LILACS, CAPES Periodicals Portal, Science Direct, SciELO y PubMed, indexado de forma aislada y asociado con los operadores booleanos 'and' y 'or', en los idiomas portugués, inglés y español. La búsqueda identificó 15.017 artículos analizados mediante un conjunto de criterios que previamente consideraban el título y palabras clave, resumen, metodología y posteriormente, la lectura completa. La revisión incluyó un total de 22 artículos que cumplieron con los criterios de elegibilidad, de los cuales el 50\% ( $\mathrm{n}=11)$ estaban en portugués y el 27,3\% $(n=6)$ con locus en la región Nordeste. Todos los estudios seleccionados presentaron resultados entre media y alta calidad metodológica. Los frutos aplicados fueron piña, açaí, plátano, cacao, coco, guayaba, guanábana, jabuticaba, limón, mango, mangaba, papaya y umbu, en forma de pulpa, jugo, extracto, azúcar, mermelada y harina. Los estudios hacen inferencias sobre los aportes resultantes de la adición de frutas en las características que se presentan en los productos, además de señalar un alto potencial de mercado. Así, el uso de frutos semiáridos brasileños en productos de kéfir fermentado es reciente y progresivo, el número de estudios muestra que su aplicación se está expandiendo y, por lo tanto, debe ser objeto de nuevos estudios como una alternativa prometedora en el mercado de alimentos potencialmente funcionales.

Palabras clave: Alimentos funcionales; Bioma de Caatinga; Fermentación; Fruto; Probióticos.

\section{Introdução}

A população, em geral, mostra-se cada vez mais preocupada em desenvolver hábitos alimentares saudáveis tendo em vista o desenvolvimento de patologias diversas associadas ao consumo de alimentos prejudiciais à saúde, sendo, portanto, essencial à valorização de produtos saudáveis e sensorialmente aceitáveis (Amorim, Lelis \& Costa, 2018; Dias, Martins \& Moreira Júnior, 2020).

Neste contexto a aplicação de culturas probióticas na produção de alimentos funcionais, com alegações de benefícios a saúde documentados em estudos relevantes, associados ainda, a praticidade, segurança microbiológica e processamento mínimo, tornam-se uma alternativa a ser considerada, como no caso do kefir, uma bebida fermentada com propriedades antiinflamatórias, antineoplásicas, antimicrobianas, com um potencial antioxidante, hipocolesterolêmico, redução de distúrbios gastrointestinais como intolerância à lactose, prevenção e redução de complicações da síndrome metabólica, dentre outros efeitos benéficos (Bourrie, Cotter \& Willing, 2018; Contim, Oliveira \& Cardoso Neto, 2018; Silva, Santos, Santana, Silva \& Conceição, 2018).

O kefir, originário do eslavo Keif que significa "bem-estar", abrolhou nas montanhas Caucasianas. Os grãos de kefir são constituídos por diversos microrganismos simbiontes, cepas de bactérias ácidos láticas e acéticas e leveduras encapsuladas por uma matriz de polissacarídeos e proteínas, denominada kefiran (Silva, Nascimento, Ferreira \& Galúcio, 2020; Silva \& Okura, 2021). A bebida fermentada de kefir é obtida por intermédio da inoculação dos grãos de kefir ou cultura inicial em determinados substratos resultando em uma bebida funcional e probiótica, de características sensoriais distintas que pode ser aplicada na elaboração de diversos produtos, como bebidas fermentadas, iogurtes, queijos, sorvetes entre outros (Tomar, Akarca, Çağlar, Beykaya \& Gök, 2020).

Além de serem obtidos de forma artesanal, podem ser cultivados a nível industrial por culturas iniciais de linhagem 
pura, na qual são isoladas cepas específicas de bactérias para inoculação, culturas liofilizadas mistas ou método russo utilizando uma cultura mãe, que resultam em um produto de características sensoriais, microbiológicas e nutricionais diferentes do fermentado por grãos de kefir, embora, possibilite a padronização dos produtos (Alves, Lelis, Cunha, \& Valente, 2019).

$\mathrm{O}$ produto obtido pela fermentação dos grãos de kefir apresenta sabor e aroma próprio, levemente gasoso, ácido, alcóolico e frutado, resultando em uma solução ácida de consistência cremosa ou líquida. O emprego dos grãos de kefir em substratos lácteos ou vegetais apresenta-se como uma opção viável, considerando que eles são recuperados no processo final da fermentação para a produção de novas bebidas, não obstante, as culturas probióticas industriais precisam ser adquiridas para cada processo de fermentação, gerando, dessa forma, custos adicionais (Santos et al., 2019).

Diversos estudos corroborando a funcionalidade do kefir são desenvolvidos a nível nacional e em escala mundial, contudo, estudos concernentes à elaboração e caracterização de produtos à base de kefir, ainda são relativamente escassos e recentes. Em contrapartida, a aplicação de frutas produzidas no semiárido brasileiro tem sido investigada no desenvolvimento dos mais diversos produtos alimentícios por disporem de características sensoriais e nutricionais apreciáveis, além de apresentar elevada atividade antioxidante, antimicrobiana, anti-inflamatória e vasodilatadora (Akonor, 2020; Brandão et al., 2020; Pletsch, Severo, Hermanns \& Preichardt, 2019).

$\mathrm{O}$ aumento das pesquisas envolvendo as frutas da caatinga possivelmente decorre da necessidade de reduzir o desperdício, devido à sazonalidade, maturação rápida, curtos períodos de safras, entre outros fatores, que reduzem a disponibilidade dessas (Souza, Tabosa, Campos, Vieira Filho \& Neder, 2018). A produção, processamento e distribuição de frutas e hortaliças gera um percentual de perdas superiores a $40 \%$ (Silva \& Pedro, 2018). No Nordeste as frutas de maior destaque são produzidas no semiárido (Ferreira \& Vieira Filho, 2021).

Uma elevada variedade de frutas é de origem nativa, são obtidas de forma extrativa ou cultivada, outras são exóticas, mas com cultivos no Nordeste brasileiro, entre as quais, destacam-se a acerola, banana, cacau, cajá, cajarana, caju, carambola, ciriguela, coco, dendê, fruta-pão, graviola, juá, mamão, maracujá, pinha, pitomba, sapoti, tamarindo e umbu, todas com potencial para o desenvolvimento de outros produtos (Brasil, 2002; Brasil, 2015).

Considerando o crescente interesse por produtos fermentados de kefir, e a expansiva aplicação de frutas, como goiaba, banana, coco, mamão, maracujá, dentre outras, em produtos alimentícios, agrupar estudos que associem as propriedades probióticas do kefir às características nutricionais e sensoriais peculiares atribuídas a essas frutas, avaliando a qualidade e o potencial de mercado dos produtos, e adicionalmente, apresentar as diversas aplicações e o tipo de processamento empregado, faz-se necessário. O presente estudo teve como objetivo compilar e analisar sistematicamente a aplicação de frutas reconhecidas como nativas e/ou cultivadas no semiárido brasileiro no desenvolvimento de produtos obtidos a partir da fermentação dos grãos de kefir.

\section{Metodologia}

\subsection{Caracterização do estudo}

Trata-se de um estudo de revisão sistemática referente à caracterização de produtos obtidos a partir de kefir com adição de frutas regionais do semiárido brasileiro (nativas e/ou cultivadas). A revisão sistemática é uma apuração científica rigorosa, com métodos sistemáticos previamente definidos para identificar todos os estudos pertinentes visando investigar e avaliar a relevância dos artigos científicos, dessa forma, obter dados e resumir os resultados (Donato \& Donato, 2019; Sampaio \& Mancini, 2007).

A revisão sistemática é replicável e neutra, tem como finalidade minimizar a obliquidade, utilizando-se de métodos claros, conduzidos por um estudo vasto e analisado especificamente, de forma crítica cada estudo, assim, a resposta ao certame 
do estudo é bem delimitada e especificada por ser metodologicamente expansiva clara e reprodutível (Donato \& Donato, 2019).

\subsection{Planejamento do estudo}

Segundo Sampaio e Mancini (2007), é preciso ponderar três etapas que antecedem a elaboração da revisão sistemática, sendo essas: definir a finalidade da revisão, identificar a literatura e selecionar os estudos que possivelmente serão incluídos na pesquisa. Seguindo a metodologia proposta, algumas etapas foram traçadas para o desenvolvimento desta pesquisa que contemplam a estruturação, o desenvolvimento e a apresentação dos resultados (Figura 1).

Figura 1 - Etapas para realização da pesquisa.

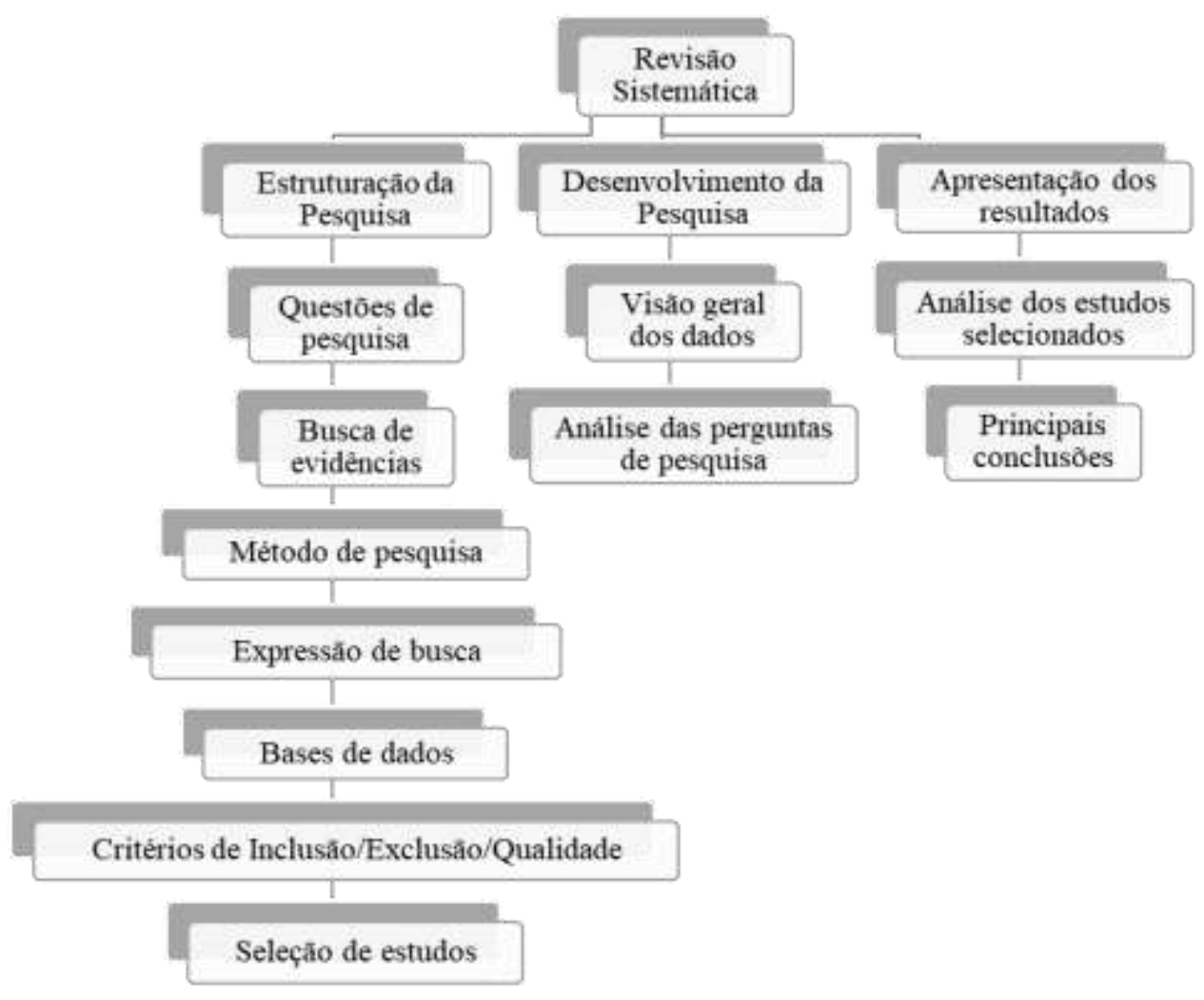

Fonte: Autores.

\subsubsection{Questões de pesquisa}

O estudo foi realizado com base nas perguntas centrais:

- QP1: Quais partes das frutas e/ou processamentos foram aplicadas para obtenção de produtos de kefir? Essa questão busca analisar as formas de aplicação das frutas (in natura), polpa, resíduos industriais (cascas, sementes); processamento (sucos, doces, geleias), dentre outros.

- QP2: A aplicação de frutas na elaboração de produtos contribuiu de forma positiva? Essa pergunta teve por finalidade investigar se a aplicação das frutas em produtos à base de kefir resultou em modificações positivas no produto.

- QP3: A adição de frutas interferiu nas características sensoriais e instrumentais do produto? Essa questão teve como propósito verificar se a adição de frutas agregou qualidade sensorial ao produto a base de kefir, visto que uma das limitações para aceitação dos alimentos obtidos a partir do kefir é seu sabor peculiar, além de verificar se promoveu alteração em atributos como cor, textura, viscosidade (instrumental e/ sensorial). 
- QP4: A adição de frutas contribuiu com os aspectos nutricionais do produto? O intuito dessa pergunta foi analisar se as frutas agregaram valor nutricional ao produto.

- QP5: Os produtos desenvolvidos apresentaram qualidade microbiológica e estabilidade mesmo após adição de frutas? Essa pergunta busca verificar segundo parâmetros microbiológicos, físico-químicos e estabilidade, se os produtos são adequados para o consumo e qual o tempo de preservação das características quando armazenados.

- QP6: A aplicação de frutas contribuiu para que o produto apresentasse potencial funcional? Essa pergunta verifica se os produtos desenvolvidos apresentam potencial antioxidante e efeito probiótico.

- QP7: Os produtos obtidos têm potencial de mercado? Essa pergunta visa verificar se os produtos desenvolvidos têm potencial para comercialização.

\subsubsection{Busca de evidência}

Posterior à definição das questões de pesquisa faz-se necessário estabelecer critérios que visem garantir a exequibilidade do estudo. Esta etapa corresponde à definição da estratégia de busca sendo substancialmente importante para assegurar que artigos relevantes sejam incluídos na pesquisa. Desta forma, utilizaram-se diversas associações de termos referentes ao assunto da pesquisa.

\subsubsection{Método de pesquisa}

Foram utilizados termos de busca, aliados a operadores lógicos em diferentes bases de pesquisa eletrônica, para ampliar o número de estudos, tornando a busca eficaz para incluir todos os estudos relevantes ou que possam ter algum impacto na revisão. Assim, foi estabelecida a sequência que se apresenta no Quadro 1.

Quadro 1 - Sequência definida para busca de estudos.

\begin{tabular}{|c|l|}
\hline Etapas & Descrição \\
\hline I & Particularizar os termos de pesquisa. \\
\hline II & Traduzir os termos para o idioma inglês. \\
\hline III & Identificar sinônimos, plurais e termos relacionados. \\
\hline IV & Empregar o operador booleano "OR” para associar os sinônimos. \\
\hline V & Empregar o operador booleano "AND” para unir termos. \\
\hline VI & Verificar os termos nos títulos, resumos e palavras-chave dos artigos. \\
\hline
\end{tabular}

Fonte: Autores.

\subsubsection{Expressão de busca}

Após definição do tema e das questões de pesquisa, foram estabelecidas as expressões de busca para inserção nas bases de dados eletrônicas. Desta forma, sinônimos foram utilizados com o auxílio de operadores booleanos para definição da expressão que, ao ser executada nas bases de dados proporcionaram o alcance resultados adequados. Assim, os termos foram selecionados e indexados nas bases de pesquisa (Quadro 2), nos idiomas inglês, espanhol e português. 
Quadro 2 - Estratégia de busca.

\begin{tabular}{|l|}
\hline Número/ Itens de pesquisa \\
\hline \#1 kefir \\
\hline \#2 fruit \\
\hline \#3 \#1 AND \#2 \\
\hline \#3 \#1 OR \#2 \\
\hline \#4 Northeastern Brazil \\
\hline \#5 'Caatinga biome' OR 'semi-arid' OR 'acerola' OR 'banana' OR 'cocoa' OR 'caja' OR 'cajarana' OR 'cashew' OR 'carambola' \\
OR 'ciriguela' OR 'coconut' OR 'palm oil' OR 'breadfruit' OR 'soursop' OR 'juá' OR 'papaya', 'passion fruit' OR 'pine cone' \\
OR 'pitomba' OR 'saputi' OR 'tamarind' OR 'umbu OR 'orange' OR 'guava' OR 'peki' OR 'pineapple' \\
\hline \#6 \#5 AND \#1 \\
\hline \#7 \#5 OR \#1 \\
\hline \#8 \#3 AND \#4 AND \#7
\end{tabular}

Fonte: Autores.

\subsubsection{Bases de dados}

Após definição dos termos de busca, para a condução da pesquisa foram selecionadas as seguintes bases de dados eletrônicas: Coordenação de Aperfeiçoamento de Pessoal de Nível Superior (Periódicos Capes), Google Acadêmico, Literatura Latino-americana e do Caribe em Ciências da Saúde (LILACS), Science Direct, Scientific Electronic Library Online (SciELO) e PubMed.

\subsubsection{Critérios de inclusão e exclusão}

Nesta pesquisa foram considerados alguns critérios de inclusão e exclusão tendo como finalidade assegurar a análise exclusiva de artigos científicos condizentes com o objetivo da revisão (Quadro 3).

Quadro 3 - Critérios de inclusão e exclusão de estudos.

\begin{tabular}{|l|l|}
\hline Critérios & \multicolumn{1}{c|}{ Descrição } \\
\hline CI1 & $\begin{array}{l}\text { Estudos que realizaram análise microbiológica, centesimal, mineral, físico-química, compostos fenólicos, } \\
\text { instrumental, sensorial e/ou estabilidade de produtos que contenham kefir com frutas do semiárido em sua } \\
\text { composição; }\end{array}$ \\
\hline CI2 & Estudos originais com textos disponíveis na íntegra sem custo; \\
\hline CI3 & Estudos em linguagem inglesa, espanhola ou portuguesa; \\
\hline CE1 & Estudos de revisão, publicações em anais de eventos, e outros estudos sem rigor científico; \\
\hline CE2 & Avaliação de patologias e/ou pesquisas realizadas em cobaias; \\
\hline CE3 & Temática não condizente ao objetivo deste estudo; \\
\hline CE4 & Preparações ou alimentos com isenção de kefir associado a frutas; \\
\hline CE5 & Publicações duplicadas. \\
\hline
\end{tabular}

Legenda: $\mathrm{CI}=$ Critérios de inclusão; $\mathrm{CE}=$ Critérios de exclusão. Fonte: Autores.

Os artigos selecionados foram analisados utilizando um conjunto de critérios de qualidade (Quadro 4). Apropriandose de uma escala de 3 pontos para responder a cada critério, variando entre "Não", "Parcialmente" ou "Sim". Assim, para cada resposta foi atribuído um valor numérico ( 0 = "Não"; $0,5=$ "Parcialmente"; 1 = "Sim"), e por fim, uma nota de qualidade é conferida para cada estudo somando os valores das respostas de cada critério avaliado (Dyba \& Dingsoyr, 2008). 
Quadro 4 - Critérios de qualidade para avaliação das publicações.

\begin{tabular}{|c|c|c|}
\hline \multicolumn{2}{|c|}{ Critério de Qualidade (CQ) } & Descrição \\
\hline CQ1 & Finalidade da pesquisa & Os objetivos do estudo estão claramente descritos e justificados? \\
\hline CQ2 & Contexto da pesquisa & Existe uma descrição adequada do contexto em que a pesquisa foi realizada? \\
\hline CQ3 & Método adotado & $\begin{array}{l}\text { O estudo apresenta informações sobre a amostra, condução das análises e metodologia } \\
\text { aplicada? }\end{array}$ \\
\hline CQ4 & Análise dos dados & $\begin{array}{l}\text { A análise dos dados foi rigorosa? Por exemplo, se o estudo fornece descrição e } \\
\text { justificativa das abordagens de análise dos dados, se foram utilizados dados suficientes } \\
\text { para apoiar as conclusões e se foram usados métodos de controle para verificar os } \\
\text { resultados. }\end{array}$ \\
\hline CQ5 & Conclusões & As conclusões são claras e respondem as finalidades da pesquisa? \\
\hline CQ6 & Críticas & $\begin{array}{l}\text { Os autores examinaram criticamente seu próprio trabalho, potenciais desvios e } \\
\text { interferências? }\end{array}$ \\
\hline CQ7 & Limitações & A credibilidade e as limitações do trabalho foram discutidas de forma explícita? \\
\hline CQ8 & Qualis Periódicos & $\begin{array}{l}\text { A revista apresenta Qualis } \mathrm{A} 1, \mathrm{~A} 2, \mathrm{~A} 3, \mathrm{~A} 4, \mathrm{~B} 1, \mathrm{~B} 2 \text { (relevância alta }=1) ; \mathrm{B} 3, \mathrm{~B} 4 \\
\text { (relevância média }=0,5) ; \mathrm{C} \text { e sem Qualis (relevância baixa }=0) .\end{array}$ \\
\hline
\end{tabular}

Fonte: Adaptado de Dyba e Dingsoyr (2008).

\subsubsection{Seleção de estudos}

A busca de estudos foi realizada entre os meses de maio a julho de 2021. A organização dos artigos utilizou o software Excel® 2013 (Microsoft Corporation, 2013) para a coleta dos dados: título do artigo, base de dados, autores, ano, local de publicação, idioma, produto desenvolvido, objetivo do artigo, metodologia, resultados e conclusão.

Diversos artigos foram analisados, inicialmente para seleção dos estudos foi aplicado o $1^{\circ}$ filtro, no qual os títulos e as palavras-chave foram verificados, sendo selecionados os que correspondiam com a temática. Foi aplicado um $2^{\circ}$ filtro concernente à análise do resumo e metodologia e por fim os estudos foram lidos na íntegra. Para análise dessas publicações, seguiram-se as questões de pesquisas estipuladas anteriormente não havendo discriminação de período de publicação destes estudos (Figura 2). 
Figura 2 - Diagrama de busca e seleção dos estudos.

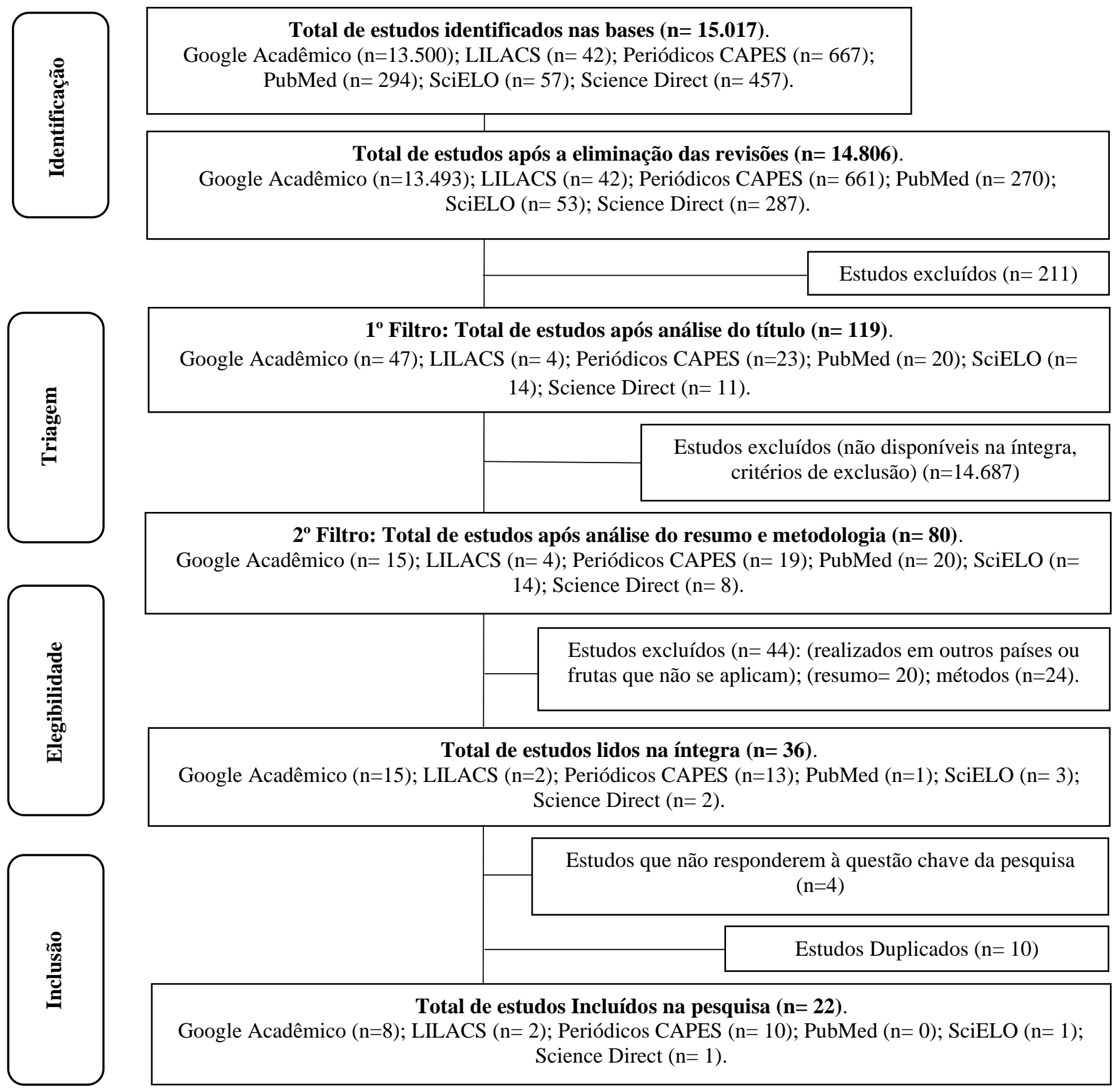

Fonte: Autores.

\section{Resultados e Discussão}

\subsection{Descrição dos estudos}

A busca nas bases de dados resultou no total de 15.017 artigos que foram analisados previamente pelo título, seguido do resumo, metodologia e posteriormente a leitura completa, por fim, 22 artigos foram selecionados atendendo aos critérios de elegibilidade, sendo excluídos os estudos que não faziam parte do escopo desta revisão. Os tipos de frutas aplicadas no desenvolvimento de produtos à base de kefir em razão dos estudos estão elencados na Figura 3. Dos estudos analisados 50\% $(\mathrm{n}=11)$ estavam na língua portuguesa e $50 \%(\mathrm{n}=11)$ na língua inglesa, apenas $27,3 \%$ ( $\mathrm{n}=6)$ com locus na região nordeste, não 
obstante, os demais estudos foram mantidos por corresponderem aos objetivos desta pesquisa e por utilizarem frutas cultivadas ou nativas do semiárido brasileiro.

Figura 3 - Levantamento das frutas nativas e cultivadas no semiárido brasileiro com aplicação nos estudos selecionados.

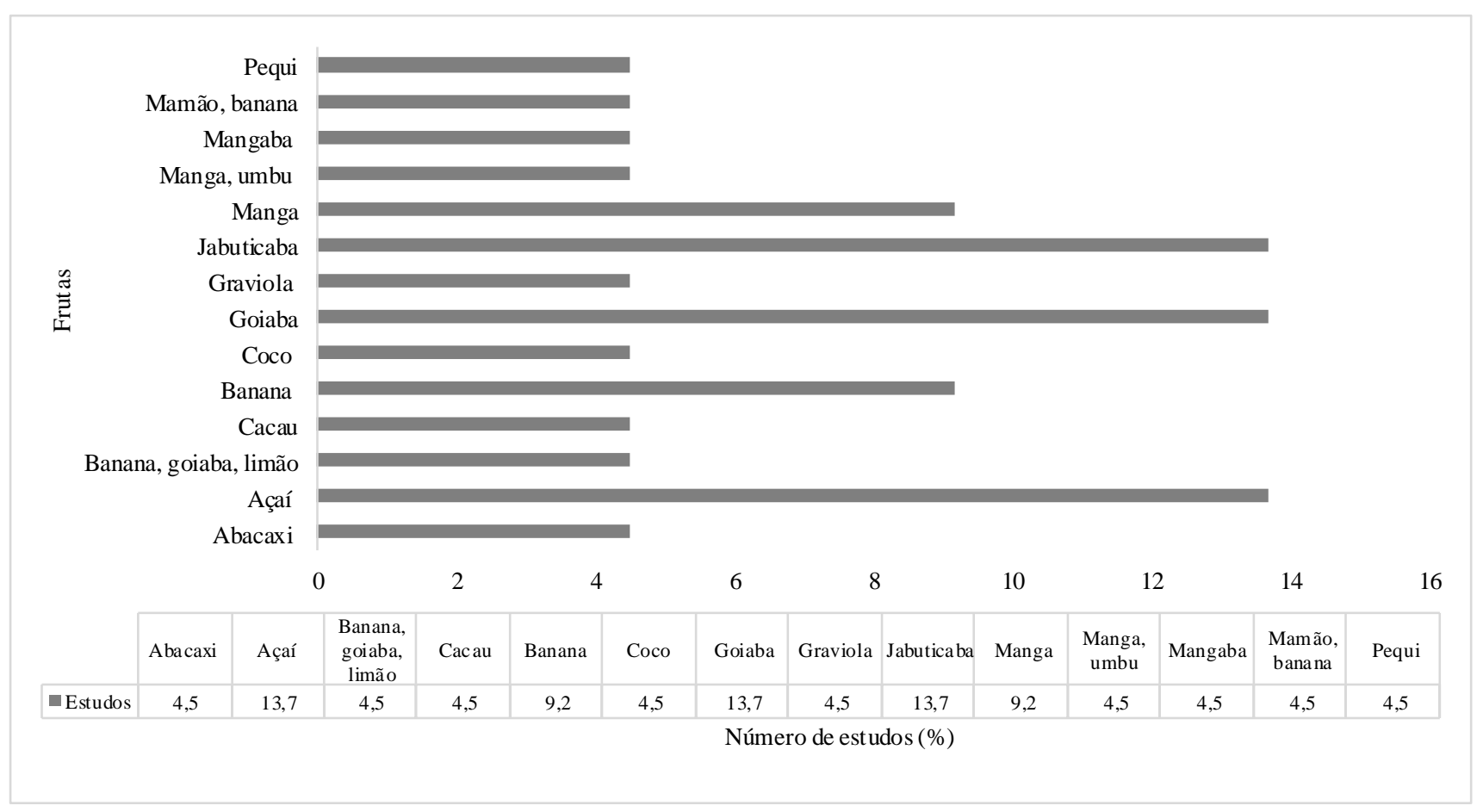

Fonte: Autores.

O levantamento dos artigos selecionados em razão do ano demonstra que a aplicação de frutas do semiárido brasileiro em associação com o kefir é recente e gradual, pois mais de 90\% dos artigos foram publicados nos últimos 4 (quatro) anos incluindo o ano 2021, até o mês de julho (Figura 4).

A síntese dos artigos selecionados na pesquisa (Quadro 5) contém as informações: Categoria do produto, identificação do estudo, título, produto desenvolvido, análises realizadas (microbiológica, centesimal, físico-química, sensorial, atividade antioxidante, dentre outras.) traduzidos para o idioma português, referência (autores, ano e local de desenvolvimento do estudo/publicação) e bases de dados (Google Acadêmico, LILACS, Periódicos CAPES, SciELO e Science Direct). 
Research, Society and Development, v. 10, n. 13, e349101321079, 2021

(CC BY 4.0) | ISSN 2525-3409 | DOI: http://dx.doi.org/10.33448/rsd-v10i13.21079

Figura 4 - Quantidade de estudos selecionados para revisão sistemática segundo o ano de publicação.

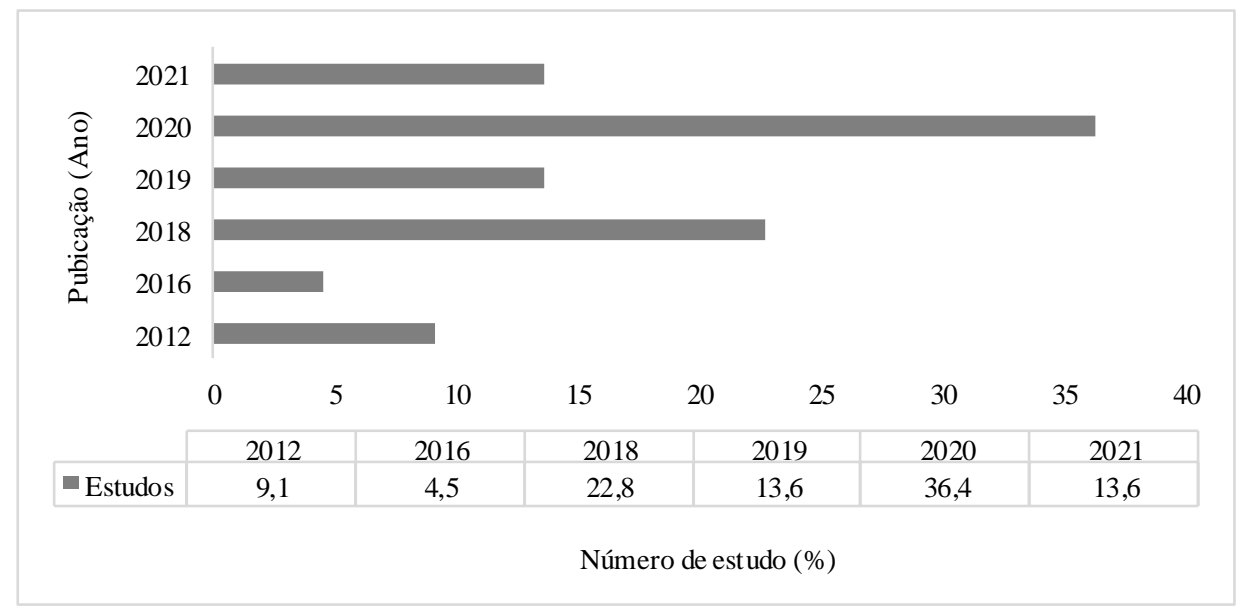

Fonte: Autores. 
Research, Society and Development, v. 10, n. 13, e349101321079, 2021

(CC BY 4.0) | ISSN 2525-3409 | DOI: http://dx.doi.org/10.33448/rsd-v10i13.21079

Quadro 5 - Identificação e aspectos gerais dos estudos na revisão sistemática.

\begin{tabular}{|c|c|c|c|c|c|c|}
\hline $\begin{array}{l}\text { Categoria do } \\
\text { produto }\end{array}$ & ID & Título & Produto & Análises & $\begin{array}{l}\text { Referência/local de } \\
\text { publicação }\end{array}$ & $\begin{array}{c}\text { Base de } \\
\text { dados }\end{array}$ \\
\hline \multirow{3}{*}{ Sorvete } & ID1 & $\begin{array}{c}\text { Parâmetros físico-químicos e aceitabilidade de } \\
\text { sorvetes desenvolvidos a partir de diferentes } \\
\text { leites fermentados por kefir, jabuticaba } \\
\text { (Myrciaria cauliflora (Mart.) O. Berg) e mel de } \\
\text { abelha silvestre. }\end{array}$ & $\begin{array}{l}\text { Sorvete de kefir com } \\
\text { jabuticaba }\end{array}$ & $\begin{array}{l}\text { Sensorial, capacidade } \\
\text { antioxidante e composição } \\
\text { centesimal. }\end{array}$ & $\begin{array}{l}\text { Ferreira et al., 2020/ } \\
\text { Curitiba, PR, Brasil. }\end{array}$ & $\begin{array}{l}\text { Google } \\
\text { Acadêmico }\end{array}$ \\
\hline & ID2 & $\begin{array}{l}\text { Desenvolvimento de sorvete de kefir com } \\
\text { polpa de manga: avaliação sensorial, físico- } \\
\text { química e de bactérias ácido láticas. }\end{array}$ & $\begin{array}{l}\text { Sorvete de kefir com polpa } \\
\text { de manga }\end{array}$ & $\begin{array}{l}\text { Microbiológica, físico-química, } \\
\text { sensorial e estabilidade. }\end{array}$ & $\begin{array}{l}\text { Parreiras, Dantas, Coelho } \\
\text { \& Souza, 2019/ Ouro } \\
\text { Preto, MG, Brasil. }\end{array}$ & LILACS \\
\hline & ID3 & $\begin{array}{c}\text { Sorvete de kefir aromatizado com frutas e } \\
\text { adoçado com mel: características físicas, } \\
\text { químicas e aceitação. }\end{array}$ & $\begin{array}{l}\text { Sorvete de kefir com frutas } \\
\text { (banana, goiaba, limão ou } \\
\text { maracujá) e mel. }\end{array}$ & $\begin{array}{l}\text { Físico-químicas, composição } \\
\text { centesimal, cor e textura } \\
\text { instrumental e sensorial. }\end{array}$ & $\begin{array}{l}\text { Januário, Oliveira, Dias, } \\
\text { Klososki \& Pimentel, } \\
\text { 2018/ Ivaiporã, PR, Brasil. }\end{array}$ & $\begin{array}{l}\text { Google } \\
\text { Acadêmico }\end{array}$ \\
\hline \multirow{3}{*}{$\begin{array}{l}\text { Picolé, Smoothie, } \\
\text { Gelado } \\
\text { comestível }\end{array}$} & ID4 & $\begin{array}{c}\text { Efeito da biomassa de kefir nas propriedades } \\
\text { nutricionais, microbiológicas e sensoriais de } \\
\text { picolés à base de manga. }\end{array}$ & Picolé de manga com kefir & $\begin{array}{l}\text { Microbiológica, centesimal, } \\
\text { físico-química e sensorial. }\end{array}$ & $\begin{array}{l}\text { Magalhães-Guedes et al., } \\
\text { 2020/ Salvador, BA, } \\
\text { Brasil. }\end{array}$ & $\begin{array}{l}\text { Google } \\
\text { Acadêmico }\end{array}$ \\
\hline & ID5 & $\begin{array}{c}\text { Análises físico-químicas e sensoriais de } \\
\text { smoothies do leite de diferentes espécies } \\
\text { fermentado por kefir, saborizados com banana } \\
\text { e maçã. }\end{array}$ & $\begin{array}{l}\text { Smoothies de leites (cabra, } \\
\text { vaca, ovelha) fermentado de } \\
\text { kefir saborizado com banana } \\
\text { e maçã. }\end{array}$ & Físico-química e sensorial & $\begin{array}{l}\text { Pattaro et al., 2020/ Rio } \\
\text { Verde, GO, Brasil. }\end{array}$ & $\begin{array}{l}\text { Periódicos } \\
\text { CAPES }\end{array}$ \\
\hline & ID6 & $\begin{array}{l}\text { Gelado comestível de kefir adicionado de } \\
\text { polpa de jabuticaba e morango. }\end{array}$ & $\begin{array}{l}\text { Gelado comestível com } \\
\text { polpa de morango e } \\
\text { jabuticaba. }\end{array}$ & $\begin{array}{l}\text { Físico-química, microbiológica, } \\
\text { antioxidante e sensorial. }\end{array}$ & $\begin{array}{l}\text { Pletsch et al., 2019/ Santo } \\
\text { Augusto, RS, Brasil. }\end{array}$ & $\begin{array}{l}\text { Periódicos } \\
\text { CAPES }\end{array}$ \\
\hline Frozen yogurt & ID7 & $\begin{array}{l}\text { Viabilidade de bactéria lática em frozen } \\
\text { adicionado de kefir. }\end{array}$ & $\begin{array}{l}\text { Frozen adicionado de kefir } \\
\text { com polpa de morango, } \\
\text { abacaxi com hortelã ou } \\
\text { maracujá. }\end{array}$ & Microbiológica e estabilidade & $\begin{array}{l}\text { Pinheiro et al., 2020/ Rio } \\
\text { Pomba, MG, Brasil. }\end{array}$ & $\begin{array}{l}\text { Google } \\
\text { Acadêmico }\end{array}$ \\
\hline $\begin{array}{l}\text { Bebida } \\
\text { fermentada } \text { kefir } \\
\text { de água }\end{array}$ & ID8 & $\begin{array}{c}\text { Desenvolvimento de bebida fermentada com } \\
\text { kefir de água em extrato de coco solúvel em } \\
\text { água (WSCE) (Cocos nucifera L.) com adição } \\
\text { de inulina. }\end{array}$ & $\begin{array}{l}\text { Bebida fermentada de kefir } \\
\text { com extrato de coco com } \\
\text { adição de inulina. }\end{array}$ & $\begin{array}{l}\text { Identificação de microrganismos, } \\
\text { caracterização físico-química, } \\
\text { centesimal e cor e viscosidade } \\
\text { instrumental. }\end{array}$ & $\begin{array}{l}\text { Alves et al., 2021/ Paraná, } \\
\text { RS, Brasil. }\end{array}$ & $\begin{array}{l}\text { Periódicos } \\
\text { CAPES }\end{array}$ \\
\hline $\begin{array}{l}\text { Bebida } \\
\text { fermentada } k e f i r \\
\text { de água }\end{array}$ & ID9 & $\begin{array}{l}\text { Viabilidade química, microbiológica e } \\
\text { sensorial de bebidas de kefir de baixa caloria e } \\
\text { sem lactose preparadas com sucos de frutas }\end{array}$ & $\begin{array}{l}\text { Bebida de kefir com sucos de } \\
\text { frutas tropicais mistos } \\
\text { (manga e umbu). }\end{array}$ & $\begin{array}{c}\text { Sensorial, composição } \\
\text { centesimal, estabilidade, vitamina } \\
\text { C e microbiológica. }\end{array}$ & $\begin{array}{l}\text { Tavares et al., 2021/ } \\
\text { Salvador, BA, Brasil. }\end{array}$ & $\begin{array}{l}\text { Periódicos } \\
\text { CAPES }\end{array}$ \\
\hline
\end{tabular}


Research, Society and Development, v. 10, n. 13, e349101321079, 2021

(CC BY 4.0) | ISSN 2525-3409 | DOI: http://dx.doi.org/10.33448/rsd-v10i13.21079

\begin{tabular}{|c|c|c|c|c|c|c|}
\hline $\begin{array}{l}\text { Categoria do } \\
\text { produto }\end{array}$ & ID & Título & Produto & Análises & $\begin{array}{c}\text { Referência/local de } \\
\text { publicação }\end{array}$ & $\begin{array}{c}\text { Base de } \\
\text { dados }\end{array}$ \\
\hline & & tropicais mistos. & & & & \\
\hline & ID10 & $\begin{array}{c}\text { Influência do açúcar mascavo orgânico e da } \\
\text { polpa de jabuticaba na fermentação do kefir de } \\
\text { água. }\end{array}$ & $\begin{array}{l}\text { Bebidas fermentadas por } \\
\text { kefir com polpa de jabuticaba }\end{array}$ & $\begin{array}{c}\text { Identificação de microrganismos, } \\
\text { físico-química, carboidrato, } \\
\text { composição mineral e cor } \\
\text { instrumental. }\end{array}$ & $\begin{array}{l}\text { Destro et al., 2019/ } \\
\text { Londrina, PR, Brasil. }\end{array}$ & SciELO \\
\hline & ID11 & $\begin{array}{c}\text { Efeito da batata yacon na aceitação sensorial } \\
\text { de kefir e viabilidade de bactérias láticas na } \\
\text { bebida. }\end{array}$ & $\begin{array}{l}\text { Bebida de kefir adicionada } \\
\text { da batata yacon com frutas } \\
\text { (mamão e banana). }\end{array}$ & Microbiológica e sensorial. & $\begin{array}{c}\text { Gonçalves, Martins, Silva } \\
\text { \& Martins, 2018/ Campos } \\
\text { dos Goytacazes, RJ, } \\
\text { Brasil. }\end{array}$ & $\begin{array}{l}\text { Periódicos } \\
\text { CAPES }\end{array}$ \\
\hline \multirow{7}{*}{$\begin{array}{l}\text { Bebida } \\
\text { fermentada } k e f i r \\
\text { de leite }\end{array}$} & ID12 & $\begin{array}{l}\text { Desenvolvimento de kefir de leite de cabra } \\
\text { com polpa de goiaba. }\end{array}$ & $\begin{array}{l}\text { Bebida de kefir com polpa de } \\
\text { goiaba. }\end{array}$ & $\begin{array}{l}\text { Microbiológica, físico-química, } \\
\text { centesimal, sensorial, viscosidade } \\
\text { e cor instrumental. }\end{array}$ & $\begin{array}{l}\text { Lima et al., 2020/ } \\
\text { Fortaleza, CE, Brasil. }\end{array}$ & $\begin{array}{l}\text { Google } \\
\text { Acadêmico }\end{array}$ \\
\hline & ID13 & $\begin{array}{l}\text { Análise de crescimento do kefir em polpa de } \\
\text { açaí. }\end{array}$ & $\begin{array}{l}\text { Bebida de kefir com polpa de } \\
\text { açaí. }\end{array}$ & $\begin{array}{l}\text { Microbiológica, físico-química e } \\
\text { estabilidade. }\end{array}$ & $\begin{array}{l}\text { Silva et al., 2020/ Porto } \\
\text { Velho, RO, Brasil. }\end{array}$ & $\begin{array}{c}\text { Google } \\
\text { Acadêmico }\end{array}$ \\
\hline & ID14 & $\begin{array}{l}\text { Caracterização e estabilidade de kefir com } \\
\text { adição de polpa de açaí. }\end{array}$ & $\begin{array}{l}\text { Bebida de kefir com polpa de } \\
\text { açaí. }\end{array}$ & $\begin{array}{l}\text { Microbiológica, físico-química, } \\
\text { centesimal, sensorial e } \\
\text { estabilidade. }\end{array}$ & $\begin{array}{l}\text { Sales et al., 2020/ } \\
\text { Fortaleza, CE, Brasil. }\end{array}$ & $\begin{array}{l}\text { Google } \\
\text { Acadêmico }\end{array}$ \\
\hline & ID15 & $\begin{array}{l}\text { Avaliação físico-química de uma bebida à base } \\
\text { de kefir saborizada com pequi. }\end{array}$ & $\begin{array}{l}\text { Bebida de kefir saborizada } \\
\text { com pequi. }\end{array}$ & $\begin{array}{c}\text { Caracterização físico-química, } \\
\text { centesimal e vitamina C. }\end{array}$ & $\begin{array}{l}\text { Gomes et al., 2020/ } \\
\text { Teresina, Piauí, Brasil. }\end{array}$ & $\begin{array}{c}\text { Google } \\
\text { Acadêmico }\end{array}$ \\
\hline & ID16 & $\begin{array}{c}\text { Desenvolvimento e aceitação sensorial de kefir } \\
\text { com geleia de goiaba e avaliação de compostos } \\
\text { bioatívos. }\end{array}$ & $\begin{array}{c}\text { Bebida de kefir com geleia } \\
\text { de goiaba. }\end{array}$ & $\begin{array}{l}\text { Sensorial, composição centesimal } \\
\text { e atividade antioxidante. }\end{array}$ & $\begin{array}{l}\text { Cavararo, Silva Junior, } \\
\text { Domingues \& Chiappini, } \\
\text { 2018/ Niterói, RJ, Brasil. }\end{array}$ & $\begin{array}{l}\text { Periódicos } \\
\text { CAPES }\end{array}$ \\
\hline & ID17 & $\begin{array}{c}\text { Avaliação microbiológica, físico-química e } \\
\text { aceitação sensorial do kefir com polpa de } \\
\text { graviola. }\end{array}$ & $\begin{array}{l}\text { Bebida de kefir com polpa de } \\
\text { graviola. }\end{array}$ & $\begin{array}{l}\text { Microbiológica, centesimal, } \\
\text { físico-química, sensorial e } \\
\text { estabilidade. }\end{array}$ & $\begin{array}{l}\text { Contim, Oliveira \& } \\
\text { Cardoso Neto 2018/ Juiz } \\
\text { de Fora, MG, Brasil. }\end{array}$ & $\begin{array}{l}\text { Periódicos } \\
\text { CAPES }\end{array}$ \\
\hline & ID18 & $\begin{array}{l}\text { Efeito da farinha de banana verde no } \\
\text { crescimento de bactérias láticas contidas nos } \\
\text { grãos de kefir. }\end{array}$ & $\begin{array}{l}\text { Bebida de kefir com adição } \\
\text { de farinha de banana verde. }\end{array}$ & $\begin{array}{c}\text { Caracterização microbiológica e } \\
\text { estabilidade. }\end{array}$ & $\begin{array}{c}\text { Moreira Junior, } \\
\text { Rodrigues, Benevenuto \& } \\
\text { Martins, 2018/ Rio } \\
\text { Pomba, MG, Brasil. }\end{array}$ & LILACS \\
\hline $\begin{array}{l}\text { Bebida } \\
\text { fermentada } k \text { efir } \\
\text { de leite }\end{array}$ & ID19 & $\begin{array}{l}\text { Leite e polpa de açaí melhoram a } \\
\text { aceitabilidade sensorial da bebida de leite } \\
\text { fermentado com kefir. }\end{array}$ & $\begin{array}{l}\text { Bebida de kefir com leite e } \\
\text { polpa de açaí. }\end{array}$ & Sensorial e físico-química. & $\begin{array}{l}\text { Nogueira, Aguiar- } \\
\text { Oliveira, Kamimura \& } \\
\text { Maldonado, 2016/ Mogi } \\
\text { Guaçu, SP, Brasil. }\end{array}$ & $\begin{array}{l}\text { Periódicos } \\
\text { CAPES }\end{array}$ \\
\hline
\end{tabular}


Research, Society and Development, v. 10, n. 13, e349101321079, 2021

(CC BY 4.0) | ISSN 2525-3409 | DOI: http://dx.doi.org/10.33448/rsd-v10i13.21079

\begin{tabular}{|c|c|c|c|c|c|c|}
\hline $\begin{array}{c}\text { Categoria do } \\
\text { produto }\end{array}$ & ID & Título & Produto & Análises & $\begin{array}{c}\text { Referência/local de } \\
\text { publicação }\end{array}$ & $\begin{array}{c}\text { Base de } \\
\text { dados }\end{array}$ \\
\hline & ID20 & $\begin{array}{l}\text { Novas bebidas de kefir à base de polpa de } \\
\text { cacau: composição microbiológica, química e } \\
\text { análise sensorial. }\end{array}$ & $\begin{array}{c}\text { Bebidas fermentadas de kefir } \\
\text { a base de cacau. }\end{array}$ & $\begin{array}{l}\text { Microbiológica, físico-química e } \\
\text { sensorial. }\end{array}$ & $\begin{array}{c}\text { Puerari, Magalhães \& } \\
\text { Schwan 2012/ Lavras, } \\
\text { MG, Brasil. }\end{array}$ & $\begin{array}{c}\text { Science } \\
\text { Direct }\end{array}$ \\
\hline \multirow{2}{*}{ Queijo } & ID21 & $\begin{array}{c}\text { Efeito da adição de inulina nas características } \\
\text { físico-químicas, microbiológicas e sensoriais } \\
\text { do queijo petit-suisse de kefir com sabor de } \\
\text { goiaba. }\end{array}$ & $\begin{array}{l}\text { Queijo petit-suisse de kefir } \\
\text { saborizado com polpa de } \\
\text { goiaba. }\end{array}$ & $\begin{array}{c}\text { Físico-química, microbiológica, } \\
\text { centesimal, cor e viscosidade } \\
\text { instrumental, vitamina C, } \\
\text { licopenos, sensorial. } \\
\end{array}$ & $\begin{array}{c}\text { Sousa et al., 2021/ } \\
\text { Limoeiro do Norte/CE } \\
\text { Brasil }\end{array}$ & $\begin{array}{l}\text { Periódicos } \\
\text { CAPES }\end{array}$ \\
\hline & ID22 & $\begin{array}{l}\text { Queijo petit suisse de kefir: uma sobremesa } \\
\text { alternativa com microrganismos de ação } \\
\text { probiótica. }\end{array}$ & $\begin{array}{l}\text { Queijo petit suisse de kefir } \\
\text { nos sabores morango, } \\
\text { mangaba, ervas e tomate } \\
\text { seco. }\end{array}$ & Sensorial & $\begin{array}{l}\text { Santos, Martins, Rocha \& } \\
\text { Moreira, 2012/ Viçosa, } \\
\text { MG, Brasil. }\end{array}$ & $\begin{array}{l}\text { Periódicos } \\
\text { CAPES }\end{array}$ \\
\hline
\end{tabular}

Legenda: ID = Código de Identificação. Fonte: Autores. 


\subsection{Critérios de qualidade dos estudos incluídos na revisão}

Após apresentação e identificação dos estudos foi realizada análise quanto aos critérios de qualidade previamente estabelecidos, incluindo: finalidade, contexto, método, análises, conclusão, críticas, limitações e Qualis da revista (Quadro 6).

No que concerne as revistas de publicação dos estudos as áreas contempladas foram tecnologia, alimentos e áreas afins, observou-se que, o estudo realizado por Nogueira et al. (2016) foi publicado na revista Acta Amazônica; o estudo desenvolvido por Pinheiro et al. (2020) foi indexado na revista de Alimentos: Ciência; Tecnologia e Meio Ambiente; os estudos de Ferreira et al. (2020) e Gomes et al. (2020) na revista Brazilian Journal of Development; Santos et al. (2012) indexado na revista de Ciência e Tecnologia de Alimentos; Destro et al. (2019) na revista de Ciência e Agrotecnologia; Cavararo et al. (2018) publicado na revista Demetra: Alimentação, Nutrição \& Saúde; Tavares et al. (2021) na CyTA - Journal of Food; Alves et al. (2021) na Food Science and Technology; Puerari, Magalhães e Schwan (2012) na Food Research International; Magalhães-Guedes et al. (2020) e Januário et al. (2018), indexados a revista International Food Research Journal; os estudos de Lima et al. (2020), Sousa et al. (2021), Pattaro et al. (2020) e Sales et al. (2020) indexados a revista Research, Society and Development; Contim, Oliveira e Cardoso Neto (2018) e Pletsch et al. (2019), publicados na Revista do Instituto de Laticínios Cândido Tostes; Moreira Junior et al. (2018), na Revista de Higiene Alimentar; Silva et al. (2020) na Saber científico; Parreiras et al. (2019) na revista Ciências Biológicas e da Saúde, e por fim, Gonçalves et al. (2018) publicado na Revista Vértices.

A avaliação da qualidade metodológica dos estudos selecionados demonstrou que os artigos apresentaram índice médio a alto (Quadro 6) evidenciando respaldo nas evidências fornecidas por estes estudos.

Quadro 6 - Descrição dos estudos quanto aos critérios de qualidade.

\begin{tabular}{|c|c|c|c|c|c|c|c|c|c|}
\hline ID* & $\begin{array}{c}\text { CQ1 } \\
\text { Finalidade }\end{array}$ & $\begin{array}{c}\text { CQ2 } \\
\text { Contexto }\end{array}$ & $\begin{array}{c}\text { CQ3 } \\
\text { Método }\end{array}$ & $\begin{array}{c}\text { CQ4 } \\
\text { Análises }\end{array}$ & $\begin{array}{c}\text { CQ5 } \\
\text { Conclusão }\end{array}$ & $\begin{array}{c}\text { CQ6 } \\
\text { Críticas }\end{array}$ & $\begin{array}{c}\text { CQ7 } \\
\text { Limitações }\end{array}$ & $\begin{array}{c}\text { CQ8 } \\
\text { Qualis** }\end{array}$ & Qualidade \\
\hline ID1 & 1 & 1 & 1 & 0,5 & 1 & 1 & 1 & 1 & 7,5 \\
\hline ID2 & 1 & 1 & 0,5 & 0,5 & 1 & 1 & 1 & 0,5 & 6,5 \\
\hline ID3 & 1 & 1 & 1 & 0,5 & 1 & 1 & 1 & 0 & 6,5 \\
\hline ID4 & 1 & 1 & 1 & 0,5 & 1 & 1 & 1 & 0 & 6,5 \\
\hline ID5 & 1 & 1 & 1 & 0 & 1 & 1 & 1 & 1 & 7 \\
\hline ID6 & 1 & 1 & 1 & 1 & 1 & 1 & 1 & 0 & 7 \\
\hline ID7 & 0,5 & 1 & 1 & 1 & 1 & 1 & 1 & 0 & 6,5 \\
\hline ID8 & 1 & 1 & 1 & 0,5 & 1 & 1 & 1 & 1 & 7,5 \\
\hline ID9 & 1 & 1 & 1 & 0,5 & 1 & 1 & 1 & 1 & 7,5 \\
\hline ID10 & 1 & 1 & 1 & 1 & 1 & 1 & 1 & 1 & 8 \\
\hline ID11 & 1 & 1 & 1 & 0 & 1 & 1 & 1 & 0 & 6 \\
\hline ID12 & 1 & 1 & 1 & 0 & 1 & 1 & 0,5 & 1 & 6,5 \\
\hline ID13 & 1 & 1 & 1 & 1 & 1 & 1 & 1 & 0 & 7 \\
\hline ID14 & 1 & 1 & 1 & 1 & 1 & 1 & 1 & 1 & 8 \\
\hline ID15 & 0,5 & 1 & 0,5 & 0,5 & 0,5 & 0,5 & 0,5 & 1 & 5 \\
\hline ID16 & 1 & 1 & 1 & 0,5 & 1 & 1 & 1 & 0,5 & 7 \\
\hline ID17 & 1 & 1 & 1 & 0,5 & 1 & 1 & 1 & 0 & 6,5 \\
\hline ID18 & 1 & 1 & 1 & 1 & 1 & 1 & 1 & 0 & 7,0 \\
\hline ID19 & 1 & 1 & 1 & 0,5 & 1 & 1 & 1 & 1 & 7,5 \\
\hline ID20 & 1 & 1 & 1 & 1 & 1 & 1 & 1 & 1 & 8 \\
\hline ID21 & 1 & 1 & 1 & 1 & 1 & 1 & 1 & 1 & 8 \\
\hline ID22 & 1 & 1 & 1 & 0,5 & 1 & 1 & 1 & 0 & 6,5 \\
\hline
\end{tabular}

Fonte: Autores. Legenda: $0=$ Não; 0,5 = Parcialmente; 1 = Sim. *ID = Código de Identificação. **Qualis: 1 = relevância alta (A1, A2; A3; A4; B1; B2); 0,5 = relevância média (B3; B4); 0 = relevância baixa (C e sem Qualis). Fonte: Autores. 


\subsection{Análises das questões de pesquisa}

Por intermédio das questões de análise da pesquisa buscou-se um maior detalhamento dos estudos e das contribuições do emprego de frutas reconhecidas como nativas e/ou cultivadas no semiárido brasileiro no desenvolvimento de produtos fermentados de kefir.

QP1 - Quais partes das frutas e/ou processamentos foram aplicadas para obtenção do produto?

Dos estudos analisados (Quadro 8), em 77\% ( $\mathrm{n}=17)$ as frutas foram aplicadas na forma de polpa (ID2, ID4, ID5, ID6, ID7, ID9, ID10, ID11, ID12, ID13, ID14, ID15, ID17, ID19, ID20, ID21 e ID22) e nas demais foram utilizadas nas formas de fruto (ID1), polpa e suco (ID3), extrato e açúcar (ID8), geleia (ID16) ou farinha (ID18). Por meio desta questão pode-se inferir que as formas de aplicação das frutas nestes produtos ainda são muito limitadas tendo em vista que, em sua maioria foram aplicadas em forma de polpa, com apenas um estudo que realizou o aproveitamento de polpas maduras (resíduo que não atendia aos requisitos de qualidade para a venda: ID4) e $23 \%$ utilizaram as frutas em diferentes formas (extrato/açúcar, geleia, suco e farinha). Urge, portanto, a necessidade de novas formas de aplicação destas frutas tendo em vista o potencial para agregar maior aceitação sensorial ao kefir e maior estabilidade quando submetidas ao processamento, buscando também verificar se as características nutricionais são preservadas.

QP2 - A aplicação de frutas na elaboração destes produtos contribuiu de forma positiva?

Observou-se na maioria dos estudos que a proporção e/ou o tipo de fruta aplicada não variou, com exceção dos estudos ID3 que usou diferentes tipos de frutas em diferentes concentrações para agregar sabor; ID17 e ID18 que diferiram entre o uso ou não da fruta; ID7 que variou os tipos de frutas e a concentração de grão de kefir; ID12, ID13 e ID14 que variou somente a concentração da fruta e ID19 que trabalhou variando a proporção de leite/fruta, somente o estudo ID18 que não observou alterações no produto adicionado de farinha de banana verde (FBV).

Em apenas alguns estudos foram elaboradas a formulação padrão/controle para comparação (ID3, ID4, ID11, ID12, ID13, ID17, ID18 e ID21), em outros, foi elaborado apenas uma formulação (ID6, ID15 e ID16) não obstante essa questão de pesquisa foi mantida, tendo em vista que, os estudos fazem inferência sobre as interferências decorrentes da adição de frutas nas características apresentadas. Nos demais estudos, os aspectos que variaram foram à concentração de kefir (ID2), o tipo de leite utilizado (ID1 e ID5); uso ou não de kefir (ID4), avaliaram apenas uma formulação (ID6, ID15, ID16); todos os ingredientes variaram com exceção do extrato de coco (ID8); variação do açúcar ou adoçante (ID9); açúcar mascavo orgânico ou convencional (ID10); presença ou não da batata yacon na formulação (ID11); formulações que diferiram quanto ao tempo e temperatura de fermentação (ID20) e proporção de inulina e açúcar (ID21).

Estes achados mostram que os estudos analisados, em sua maioria, retratam sobre as contribuições da aplicação de frutas na qualidade sensorial e nutricional do produto, podendo ser explicado em razão das frutas apresentarem características sensoriais, nutritivas, biofuncionais, dentre outras, que, quando mantidas após o processamento, podem contribuir para a melhoria dos produtos desenvolvidos (Akonor, 2020; Brandão et al., 2020).

QP3 - A adição de frutas interferiu nas características sensoriais e instrumentais do produto?

Dentre os estudos explanados, os que apresentaram análise sensorial (ID1- análise descritiva, escala hedônica de 7 pontos e intenção de compra, ID2, ID3, ID4- índice de saliência de Smith e escala hedônica, ID5- discriminativo e afetivo de intenção de compra, ID6, ID9, ID11, ID12, ID14, ID16- intenção de compra: escala de 7 pontos, ID17, ID19, ID20, ID21 e ID22) obtiveram valores que indicam média e boa aceitação por escala hedônica de 9 pontos $(1=$ não gostei muito e $9=$ gostei muitíssimo) atributos avaliados (aparência, aroma, cor, doçura, textura e/ou aceitação geral), e intenção de compra por escala 
de 5 pontos ( 1 = certamente não compraria e 5 = certamente compraria) (ID1, ID3, ID5, ID6, ID9, ID12, ID14, ID16, ID21 e ID22). Os estudos que avaliaram a qualidade sensorial dos produtos obtiveram aceitação e intenção de compra acima do valor médio ("indiferente") para pelo menos uma das formulações com agregação das frutas. Esses achados corroboram para o potencial de mercado destes produtos, visto que os aspectos sensoriais são essenciais para escolha de um produto alimentício, embora apenas 4 estudos tenham apresentado Índice de Aceitabilidade superior a 70\%, resultado que indica que o produto é considerado aceitável em termos de propriedades sensoriais, conforme Dutcosky (2013).

As análises instrumentais de cor, textura e viscosidade são importantes, pois, em conjunto com as percepções sensoriais são determinantes para caracterização e atuam no controle de qualidade dos produtos (Miranda, Oliveira, Braga \& Damaceno, 2021). No entanto, apenas alguns estudos analisados apresentaram essas características nos produtos (ID3, ID8, ID9, ID10, ID12, ID21) alcançando resultados positivos e consensuais com os resultados sensoriais, com exceção do estudo ID10 que não realizou análise sensorial. Destacam-se os estudos ID3 e ID12, constatando que as concentrações ou adição de fruta não interferiram, ou intensificaram os aspectos de viscosidade, textura ou cor dos produtos.

QP4 - A adição de frutas contribuiu com os aspectos nutricionais e físico-químicos do produto?

Os estudos que realizaram a determinação da composição centesimal (ID1, ID3, ID4, ID6, ID8, ID9, ID10, ID14, ID15, ID16 e ID21) e dos aspectos físico-químicos dos produtos (ID2, ID3, ID4, ID5, ID6, ID8, ID9, ID10, ID12, ID13, ID14, ID15, ID17, ID19, ID20 e ID21), em sua maioria, não apresentaram alterações nesses parâmetros, com exceção para o estudo ID3 cujas alterações para esses parâmetros são consistentes com o tipo e proporção de frutas aplicadas, com destaque para o sorvete de limão que apresentou teores mais elevados de lipídios em detrimento das demais formulações. ID4 com efeitos positivos da agregação da biomassa de kefir ao picolé de manga que resultou em conteúdo de proteínas e cinzas mais elevado e redução do pH e sólidos solúveis. ID6 que apresentou teores significativos de proteínas. ID8 em que a utilização do extrato solúvel da água de coco possibilitou a obtenção de um produto com baixo teor calórico e proteico e elevado de lipídios. ID9 apresentou baixo teor de lipídios. ID12, verificou que a proporção de polpa de frutas mais elevada resultou em redução de sólidos solúveis, pH, gordura e proteína. ID14 a concentração de açaí influenciou na acidez titulável. ID19 mostrou que a concentração de polpa de açaí reduziu o pH dos produtos. Dessa forma, a maioria dos estudos agregou valor nutricional ao produto, e se apresentaram em conformidade com a legislação.

Cabe salientar que apenas um estudo, ID10, determinou a composição mineral, obtendo resultados significativos com exceção de alguns nutrientes (K, Ca, S e Na). Além de ID15 e ID21 que determinaram o teor de vitamina C, observando aumento durante o período de estocagem, diferente do que foi reportado por ID9 que relatou obter redução deste parâmetro.

Considerando a crescente busca dos consumidores por alimentos com elevada qualidade nutricional, aspectos físicos e químicos próprios dos produtos, e que atendam a legislação, essas caracterizações são essenciais ao desenvolvimento destes produtos servindo de base para despertar o interesse por parte das indústrias alimentícias. Esses resultados denotam qualidade nutricional e de seus aspectos físico-químicos para a maioria dos estudos em que esses parâmetros foram analisados. A investigação concernente aos micronutrientes é insuficiente, e embora, não seja investigada na maioria dos estudos, há um vasto conhecimento na literatura, mostrando que o produto do kefir (devido, por exemplo, a presença de Lactobacillus kefir) é capaz de produzir vitaminas durante o processo de fermentação. Além disso, as frutas apresentam em sua composição vitaminas e minerais. A investigação quanto à aplicação de frutas em produtos à base de kefir é necessária para determinar se essas contribuem com o aumento desses nutrientes nesses produtos (Magalhães-Guedes et al., 2020).

QP5 - Os produtos desenvolvidos apresentam qualidade microbiológica e estabilidade mesmo após adição de frutas?

No que se refere aos aspectos microbiológicos, o Ministério da Agricultura, Pecuária e Abastecimento (MAPA), por 
meio do Regulamento Técnico de Identidade e Qualidade de leites fermentados, disposto na Instrução Normativa nº 46, de 23 de outubro de 2007, define o kefir como leite fermentado e determina que os microrganismos presentes devam ser viáveis, ativos e abundantes no produto obtido durante a validade, com contagem mínima de $10^{7}$ (UFC/g) de bactérias láticas totais; $10^{4}$ (UFC/g) de leveduras específicas e de 0,5 a 1,5 de Etanol (\% v/m) (Brasil, 2007). Nos estudos analisados (ID3, ID4, ID6, ID7, ID9, ID11, ID12, ID14, ID17, ID20 e ID21) para contagem de Bactérias Ácido Láticas (BAL), ID4, ID9, ID10 e ID20 realizaram identificação dos microrganismos, ID9 e ID21 contagem de leveduras, etanol (ID20), verificou que os produtos se apresentaram em conformidade com a legislação apresentando efeito probiótico.

Outro fator determinante da qualidade é a verificação de contaminação do kefir, tendo em vista, que diversos fatores como, manipulação, falta de higiene dos utensílios, dentre outros, podem contribuir para essa ocorrência. Neste aspecto, observou-se que ID6, ID12, ID13, ID14 e ID21 apresentaram qualidade microbiológica sendo designados como seguros para o consumo, não obstante ID7 e ID11 apresentaram contaminação do produto (por contagem de coliformes totais e termotolerantes). Observou-se que poucos estudos apresentaram análise microbiológica de patógenos, mesmo tendo realizado análise sensorial, o que pode conferir risco aos avaliadores em caso de contaminação, embora as características físicas e químicas do produto sejam desfavoráveis para o desenvolvimento de microrganismos patógenos, não os isenta de possíveis contaminações (Pinheiro et al., 2020).

A estabilidade durante o armazenamento dos produtos desenvolvidos foi verificada em poucos estudos (ID2- 29 horas, ID6- 60 dias, ID7- 15 dias, ID9- 30 dias, ID10- 56 horas, ID11- 28 dias, ID13- 96 horas, ID17- 28 dias, ID18- 28 dias e ID21- 28 dias de armazenamento), nestes, (ID2, ID6) apresentaram estabilidade quanto aos parâmetros estudados, em especial ID6 com elevação no índice de aceitação para 90\% para o atributo de textura. Não obstante, no estudo ID9, quanto aos parâmetros instrumentais de cor, observaram diferença significativa (a partir de 10 dias), percebidas sensorialmente apenas após 20 dias de armazenamento. ID10 apresentou modificação da cor ao longo do armazenamento, com cor mais vívida (decorrente possivelmente da jabuticaba), além disso, elevado teor de acidez e redução a teores mínimos de sólidos solúveis após 45 horas. ID11 apresentou quanto às características microbiológicas, conformidade com a legislação apenas após 28 dias de estocagem. ID17 observou redução na contagem de microrganismos até 21 dias permanecendo em conformidade com a legislação durante todo o período avaliado, o pH variou apenas em 28 dias e a acidez titulável elevou até valores acima da legislação. ID18 não apresentou efeitos positivos no crescimento de lactobacilos durante estocagem. ID21 observou redução na contagem de BAL e alterações de cor durante o armazenamento para todas as formulações (do vermelho para o amarelo), proveniente possivelmente da adição de goiaba, assim quanto mais tempo o produto permaneceu armazenado, mais intensa a cor amarela.

Em termos gerais, os estudos apresentaram uma redução do $\mathrm{pH}$ e elevação da acidez, principalmente nos produtos em que se analisou o tempo de vida útil, processo esse esperado, devido a ação do kefir na fermentação e aproveitamento dos ácidos orgânicos como fonte de carbono e energia, reduzindo o $\mathrm{pH}$, como exemplo, a produção de ácido lático decorrente da fermentação dos microrganismos presentes nos grãos de kefir (Araújo et al., 2019; Gonçalves et al., 2018).

A manutenção das características do produto durante a estocagem é importante para conferir potencial de mercado para a industrialização, verificações de tempo e temperatura, e o efeito das frutas aplicadas promovendo condições ótimas que favoreçam uma maior durabilidade destes produtos, são essenciais. Cabe ressaltar, que no desenvolvimento dos produtos não foram utilizados aditivos com a finalidade de conservação, embora tenham sido empregadas fibras visando conferir características prebióticas ao produto (goma xantana e inulina - ID8, goma xantana e frutooligossacarídeo - ID9 e inulina ID21) que, em consequência, nas concentrações adequadas, podem conferir uma maior estabilidade por promover o crescimento dos microrganismos benéficos, assim como apresentar características de viscosidade, estabilidade, entre outros, preservando as características do produto por mais tempo, conforme foi verificado pelos estudos supracitados. Assim, o 
conhecimento da estabilidade desses produtos é essencial para o planejamento da produção, comercialização e consumo de kefir como alimento funcional (Araújo et al., 2019).

QP6 - A aplicação de frutas contribuiu para que o produto apresentasse potencial funcional?

Poucos estudos averiguaram a atividade antioxidante, compostos fenólicos (ID1, ID6, ID16 e ID21) observando efeitos positivos, associados possivelmente a adição das frutas para pelo menos uma formulação, especialmente ID6 que apresentou atividade antioxidante mais elevada no gelado comestível de kefir quando adicionado de polpas de frutas de morango e jabuticaba e ID16 que verificou teores mais elevados de compostos fenólicos quando comparado com a matéria prima aplicada (geleia de goiaba e fermentado de kefir). Estes achados indicam uma possível interação entre as propriedades antioxidantes presentes naturalmente nas frutas e no produto fermentado de kefir que resulta na elevação desses teores no produto final.

Em geral, os estudos mostram potencial probiótico indicando que as frutas apresentaram em sua maioria, efeito positivo na viabilidade dos microrganismos presentes nos produtos à base de kefir, além disso, outros ingredientes podem ter contribuído para esse teor, como adição de açúcar, mel, inulina, goma xantana, frutooligossacarídeos, dentre outros.

QP7 - Os produtos obtidos têm potencial de mercado?

Conforme análise detalhada das características investigadas, que são determinantes para o potencial de venda desses produtos, observa-se, que no geral, os estudos apontam um elevado potencial. Todavia, a quantidade limitada de estudos e de análises de viabilidade econômica não fornece subsídios suficientes para inferir o potencial de mercado destes produtos.

A grande dificuldade na comercialização decorre possivelmente, da falta de padronização da composição dos grãos de kefir. Características físicas, químicas, viscosidade, sabor e textura estão condicionados à região, condições de tempo e temperatura, tamanho do inóculo, entre outros e que, portanto, limitam a sua aplicação a nível industrial, muito embora, esta possa ser realizada por meio de cultura inicial e outros métodos de cultivo utilizados de forma industrial, conferindo maior estabilidade, mas também um custo adicional (Araújo et al., 2017; Santos et al., 2019).

Algumas frutas utilizadas exibem características intrínsecas de acidez elevada (comuns em frutas nativas do semiárido), o que pode contribuir para rejeição ou aceitação quando comparado a aplicação de frutas menos ácidas, conforme observado em ID3. As poucas formas de aplicação investigadas também podem se mostrar como aspectos desfavoráveis, embora na maioria dos estudos já desenvolvidos, e explanados nessa revisão, estas características não tenham interferido negativamente na caracterização dos produtos.

\subsection{Discussão dos estudos selecionados}

Ferreira et al. (2020) - Artigo ID9 - desenvolveram duas formulações de sorvete e observaram em relação aos parâmetros sensoriais (sabor, cor, aroma, odor, textura, aparência global) que os produtos desenvolvidos possuíam características distintas devido ao tipo de leite utilizado (vaca, cabra) e ingredientes pouco difundidos no mercado (mel, jabuticaba). Com destaque para o sorvete produzido com índices satisfatórios nas 5 categorias avaliadas e o leite caprino que alcançou índices satisfatórios em 3 atributos avaliados com frequência superior a 70\% (índice de aceitabilidade). Na intenção de compra, $32 \%$ dos avaliadores "talvez comprasse" o sorvete com leite bovino e $26 \%$ dos avaliadores "certamente não comprariam" o sorvete com leite caprino. No que concerne à composição centesimal, o produto apresentou-se como um alimento hipercalórico, hiperglicídico, normoproteico e hipolipídico. Para o teor de antocianinas totais e capacidade antioxidante os resultados mostram-se semelhantes entre as formulações, com valor nutricional agregado e capacidade antioxidante significante. Ressalta-se que os resultados obtidos no estudo podem sofrer interferência dos outros ingredientes 
utilizados como citado pelos autores, assim uma investigação mais precisa exigiria que o fator variável na formulação fosse apenas à jabuticaba.

Parreiras et al. (2019) - Artigo ID2 - desenvolveram duas formulações de sorvete (com concentração de grãos de kefir a $5 \%(\mathrm{~m} / \mathrm{v})$ e $10 \%(\mathrm{~m} / \mathrm{v})$ empregados para sua elaboração) e verificaram conforme a análise sensorial, que as formulações foram bem aceitas $(p>0,05)$ em todos os atributos com aceitação média alocada entre os termos hedônicos "gostei ligeiramente" e "gostei moderadamente". A contagem BAL, realizadas antes do congelamento (T1-0), após o congelamento final (T2-29 h), após uma semana de congelamento (T2-168 h) mostrou que os produtos estavam em conformidade com a legislação mesmo quando estocado conferindo assim manutenção da viabilidade dessas bactérias durante o armazenamento e estabilidade microbiológica ao produto. Já as características físico-químicas não dispõem de regulamentação suficiente para respaldar os dados obtidos com este tipo de produto (sorvete fermentado com kefir) embora o pH $(3,83$ a 4,85$)$ e acidez titulável $(0,74$ a 1,02) não diferiram $(p>0,05)$ entre as formulações avaliadas.

Januário et al. (2018) - Artigo ID3 - elaboraram quatro formulações de sorvete (banana, maracujá, goiaba e limão) para comparar com um sorvete industrial (abacaxi) e constataram com relação a caracterização físico-química e centesimal que os sorvetes de kefir, apresentaram maior resistência ao derretimento, mais firmes, consistentes, maior viscosidade e maior acidez $(\mathrm{pH} 5,6-6,1)$ frente ao sorvete comercial $(\mathrm{p} \leq 0,05)$ o sorvete de maracujá apresentou menor $\mathrm{pH}(\mathrm{p} \leq 0,05)$. As formulações apresentaram também teores de proteínas mais baixos (3,49-4,74 g/100 g), assim como, lipídios (3,54-6,85 g/100 g) divergindo apenas para o sorvete de limão que apresentou maior teor de lipídios (9,9 g/100 g) e cinzas (0,78-1,05 g/100 g) do que o produto comercial. Para os parâmetros de cor (maracujá e limão) apresentaram cor semelhante ao comercial (amarelo esverdeado) ( $p>0,05)$. As análises sensoriais e instrumentais revelaram que o sorvete de banana apresentou firmeza, coesão e aceitação geral semelhante ao produto comercial, com menores pontuações de aparência e textura. Embora os outros sorvetes apresentassem menor aceitação geral que o sorvete comercial, recebeu pontuações entre "gostei ligeiramente" a "moderadamente," no que se refere a intenção de compra os valores foram alocados em "provavelmente compraria" para todas as formulações. Assim, foram desenvolvidos sorvetes com sabor de frutas, mel e com leite fermentado de kefir com características semelhantes a um produto disponível no mercado. Este estudo demonstrou que a composição físico-química e centesimal variou de acordo com a composição e concentração de fruta aplicada.

Magalhães-Guedes et al. (2020) - Artigo ID4 - elaboraram um picolé de manga suplementado com biomassa de kefir, e um controle (apenas com manga), dentre os principais resultados obtidos, houve redução nos valores de pH e sólidos solúveis durante 24 h de fermentação. O conteúdo de proteína aumentou após 24 h de fermentação. A formulação com adição de kefir continha um espectro diverso de bactérias ácido láctico que após a fermentação permaneceu inalterada, apresentou contagem de $1,0 \times 10^{6} \mathrm{UFC} / \mathrm{mL}$ de leveduras, $1,0 \times 10^{10} \mathrm{UFC} / \mathrm{mL}$ de bactéria ácido láctica e $1,0 \times 10^{8} \mathrm{UFC} / \mathrm{mL}$ de bactéria ácido acética. Os atributos sensoriais foram pontuados entre 7,6 e 8,4 (moderado a extremo o atributo de sabor destacou-se para ambas as formulações. Destacam-se que a suplementação com grãos de kefir aumentou as características nutricionais, especialmente o teor de proteínas $(\mathrm{p}<0,05)$, além do atributo sensorial sabor e da viabilidade dos microrganismos presente no produto que o caracteriza como "alimento com potencial probiótico.

Pattaro et al. (2020) - Artigo ID5 - elaboraram três formulações de smoothie com diferentes tipos de leite (cabra, vaca e ovelha). Sensorialmente o smoothie com leite de cabra fermentado por kefir se destacou pela maior pontuação para diversos parâmetro de aceitação e intenção de compra (42,7\% de aceitação e 18,8\% de rejeição). O pH $(4,49$ a 4,53) das formulações

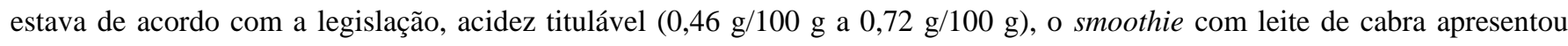
menor acidez, sólidos solúveis ( $10^{\circ}$ Brix a $13^{\circ}$ Brix), o de ovelha com sólidos solúveis mais baixo. A elaboração de smoothie com leite fermentado de diferentes espécies por kefir saborizado com banana e maçã é viável, e os níveis de aceitação e parâmetros físico-químicos variaram conforme o substrato. 
Pletsch et al. (2019) - Artigo ID6 - o gelado comestível fermentado de kefir com adição de morango e jabuticaba apresentou teores significativos de compostos fenólicos e atividade antioxidante, contagem adequada de bactérias láticas $(1,0 \mathrm{x}$ $10^{8} \mathrm{UFC} / \mathrm{g}$ ) e leveduras (7,6 x $\left.10^{7} \mathrm{UFC} / \mathrm{g}\right)$ durante o armazenamento. O produto apresentou acidez titulável em conformidade com a legislação, teor significativo de proteína bruta e de compostos fenólicos e baixo teor de antocianinas. Atividade antioxidante mais elevada em detrimento dos valores observados para as polpas de jabuticaba e morango. Quanto aos aspectos sensoriais, realizado nos tempos 0, 30 e 60 dias de armazenamento, apresentou aceitabilidade superior a 80\%, nos atributos textura, odor, sabor e cor com aumento para $90 \%$ na textura no $60^{\circ}$ dia. Para a intenção de compra, o produto apresentou $82 \%$. Assim, este estudo demonstrou o potencial microbiológico, funcional e sensorial do produto desenvolvido.

Pinheiro et al. (2020) - Artigo ID7 - consistiu no desenvolvimento de frozen yogurt de kefir (20 e 50\% de grãos de kefir) e adição de polpa de frutas de abacaxi com hortelã, maracujá e morango. A amostra de kefir apresentou contagens superiores $1100 \mathrm{NMP} / \mathrm{g}$ para coliformes totais e termotolerantes (não conforme a legislação) e valores inferiores a 3,0 NMP/g para E. coli (em conformidade com a legislação). Contagem de BAL nos T0 e T15 dias após a fabricação, indicaram que um consumo de $100 \mathrm{~g}$ equivale a ingestão de $10^{8} \mathrm{UFC} / \mathrm{g}$, sendo suficiente para se obter um alimento com potencial funcional. Assim, os produtos apresentaram características microbiológicas insatisfatórias caracterizando-os como impróprios para o consumo, não obstante, contagens de BAL estavam em conformidade com a legislação com potencial funcional.

Alves et al. (2021) - Artigo ID8 - estudou duas bebidas fermentadas de kefir com extrato de coco e adição de inulina (açúcar de coco $=2,0 \%$, inulina $=3,0 \%$ e goma xantana $=0,01 \%$ p/v; açúcar de coco $=10,0 \%$, inulina $=2,0 \%$, goma xantana $=$ $0,26 \% \mathrm{p} / \mathrm{v}$, analisados nos tempos T0 e T24), verificando que a inulina favoreceu o crescimento dos grãos de kefir, aumento da viscosidade, rendimento e acidez da bebida, além disso, o açúcar de coco contribuiu para viabilidade e manutenção dos microrganismos. Os aspectos nutricionais revelaram que o produto obtido apresentou baixo teor calórico e proteico e elevados níveis de lipídios característicos do substrato utilizado. A cor teve variação $(\mathrm{p} \leq 0,05)$ para luminosidade em 24 h. Portanto, a utilização do extrato de coco solúvel em água mostrou-se uma opção considerável como substrato tecnológico e bioprocessado para manutenção da viabilidade da microbiota dos grãos de kefir.

Tavares et al. (2021) - Artigo ID9 - ao desenvolverem bebidas de kefir com polpas de frutas mistas (manga e umbu) com adoçante ou açúcar, dentre outros ingredientes (goma xantana, frutooligossacarídeos e ácido ascórbico) avaliadas durante 30 dias, averiguaram que ambas as bebidas apresentaram potencial probiótico durante o período de estocagem (contagem de BAL e leveduras em conformidade com a legislação) e boa aceitação sensorial, a formulação com adição de açúcar apresentou maior aceitação e intenção de compra. Análise instrumental de cor mostrou diferença significativa que só foram percebidas nas avaliações sensoriais após 20 dias de armazenamento. Ácido ascórbico apresentou redução durante o armazenamento para ambas às bebidas (23,63\% para bebida adoçada com sacarose e 15,57\% para bebida adoçada com estévia). Com melhores resultados observados para a formulação contendo adoçante que apresentou menor teor calórico e boa aceitação sensorial, como um produto potencial de baixa caloria considerando dietas de restrições alimentares.

Destro et al. (2019) - Artigo ID10 - analisando bebidas fermentadas por kefir com polpa de jabuticaba, com adição de açúcar mascavo orgânico ou convencional, verificaram que o uso de açúcar orgânico influenciou na composição mineral. As características instrumentais de cor apresentaram tendência de aumento ao longo do armazenamento, observando que o uso da jabuticaba favoreceu o desenvolvimento de produtos com cor mais vívida, menor luminosidade (menor perda de cor), mais avermelhados e menos amarelos. Foram observadas diferenças nos grãos desenvolvidos com e sem jabuticaba e, também, nos microrganismos presentes. Ambas as formulações resultaram em produtos ácidos, com redução no teor de sólidos solúveis a níveis mínimos após $45 \mathrm{~h}$ de inoculação.

Gonçalves et al. (2018) - Artigo ID11 - analisaram uma bebida de kefir adicionada de batata yacon com mamão e banana, e bebida padrão (sem batata yacon) verificaram que as formulações apresentaram qualidade microbiológica e 
contagem de BAL (contagem acima de $10^{7} \mathrm{UFC} / \mathrm{mL}$ ) em conformidade com a legislação sanitária apenas após 28 dias de armazenamento, que decorre possivelmente a fase estacionária ou morte dos microrganismos presentes na bebida. A análise sensorial demonstrou que, ambas as formulações apresentaram valores próximos à região de indiferença, porém, a bebida com batata yacon melhorou a aceitação no sabor e impressão global.

Lima et al. (2020) - Artigo ID12 - analisaram em bebidas de kefir de leite (cabra) com polpa de goiaba, os aspectos microbiológicos de contagem de BAL mostrando que o produto apresenta potencial probiótico para todas as formulações. As concentrações de polpa $(0 \%, 5 \%, 15 \%$ e $25 \%)$ interferiram em alguns parâmetros físico-químicos e instrumentais (acidez, proteína, viscosidade, cor). Quanto aos parâmetros sensoriais, todas as formulações se encontravam na zona de aceitação (escores 6 a 9 na escala hedônica) para os parâmetros cor, aparência, sabor, cheiro, consistência e impressão global, no entanto, a formulação com maior concentração de polpa se destacou pela alta aceitação dos consumidores, além da intenção de compra positiva, dessa forma, as bebidas apresentaram elevado potencial para o mercado.

Silva et al. (2020) - Artigo ID13 - avaliaram a bebida de kefir com polpa de açaí, observando qualidade microbiológica dos substratos empregados, em que a adição da polpa contribuiu para o crescimento da colônia de kefir nos diferentes tempos de fermentação ( 24 h, 48 h, 72 h e 96 h) e concentrações ( $0 \%, 25 \%, 50 \%, 75 \%$ e 100\%), com destaque para as formulações $100 \%$ açaí (48 h) e 50\% e 25\% (96 h). Valores de pH indicam acidez semelhante em todas as formulações, com redução após 24 horas, mantendo-se estáveis no resto do período de avaliação, sólidos solúveis foram baixos permanecendo constante no período. Foi observado maior crescimento de microrganismos na formulação com $100 \%$ de açaí em 48 horas e nas formulações com 50\% e $25 \%$ de açaí em 96 horas, apresentando dessa forma, potencial para o desenvolvimento de bebidas fermentadas de kefir.

Sales et al. (2020) - Artigo ID14 - elaboraram bebidas de kefir com polpa de açaí em diferentes condições de tempo (24 h- 48 h) e concentrações de polpa (10\% - 30\%) verificando por meio de parâmetros físico-químicos que as bebidas se encontravam em conformidade com a legislação. A concentração de polpa de açaí influenciou na acidez e aceitação. Os parâmetros sensoriais apresentaram boa aceitação e intenção de compra. A bebida fermentada em 36 horas adicionada de $20 \%$ de polpa de açaí exibiu a melhor combinação avaliada para as características de acidez e aceitação, apresentando também melhores pontuações para intenção de compra com maior frequência de respostas nas categorias 4 (possivelmente compraria) e 5 (certamente compraria), compactuando com a formulação controle (sem adição de polpa de açaí). No que concerne ao armazenamento (45 dias), as formulações apresentaram acidez acima da legislação a partir de sete dias, entretanto, a contagem de BAL permaneceu viável durante o armazenamento (em torno de $10^{7}$ a $10^{8} \mathrm{UFC} / \mathrm{g}$ ), desse modo, produziu uma bebida com potencial probiótico.

Gomes et al. (2020) - Artigo ID15 - produziram uma bebida fermentada de kefir saborizado com pequi, realizando a caracterização físico-química e centesimal do produto, obtendo valores de $\mathrm{pH} 4,77$, atividade de água $0,83 \%$, acidez titulável 0,55\%, vitamina C $3,45 \%$, sólidos solúveis $14,1 \%$, umidade $82 \%$ e cinzas $0,66 \%$. Os autores concluíram que é possível elaborar uma bebida láctea funcional, com qualidade tecnológica e nutricional a partir do leite fermentado.

Cavararo et al. (2018) - Artigo ID16 - desenvolveram bebida de kefir com geleia de goiaba obtendo aceitação com pontuações alocadas entre "gostei muito" e "gostei moderadamente" o atributo mais apreciado foi sabor (37\%). A intenção de compra relevou média ponderada de 3,03, correspondente à categoria "compraria frequentemente". Observou-se aumento da atividade antioxidante do produto em $74,5 \%$ e 16,5\%, quando comparado ao kefir e à geleia puros, respectivamente. Os resultados mostram que a adição de 30\% de geleia de goiaba elevou a atividade antioxidante, compostos fenólicos e os carotenoides totais da bebida de kefir. O produto apresentou boa aceitação e intenção de compra pelos avaliadores.

Contim; Oliveira e Cardoso Neto (2018) - Artigo ID17 - elaboraram uma bebida de kefir com polpa de graviola e uma bebida controle (sem adição da polpa de graviola) avaliada nos tempos $0,7,14,21$ e 28 dias, conforme as análises 
microbiológicas, verificaram contagens similares para todos os grupos de bactérias $\left(10^{9} \mathrm{UFC} / \mathrm{mL}\right)$ com redução de dois ciclos logaritmos ao final de 28 dias de armazenamento. A adição da polpa de fruta e açúcar ao kefir não interferiu no comportamento da microbiota analisada. Os valores de pH não variaram $(\mathrm{p}>0,05)$ durante 21 dias, embora tenham verificado elevação na acidez progressivamente durante todo período, somente no $28^{\circ}$ dia de estocagem refrigerada, observou-se que o tipo de produto (controle e bebida) influenciaram $(\mathrm{p}<0,05)$ na variação do $\mathrm{pH}$, com valores mais baixos para a bebida com adição de polpa. A acidez titulável aumentou progressivamente durante a estocagem para valores acima do previsto na legislação. Quanto à caracterização sensorial, a bebida apresentou elevada aceitabilidade (médio 8,3) indicando potencial para comercialização.

Moreira Junior et al. (2018) - Artigo ID18 - estudaram bebida de kefir com adição de farinha de banana verde (FBV) na concentração de $2 \%$ e investigaram a viabilidade de bactérias lácteas durante o armazenamento $(0,7,14$ e 28 dias). Não foi observada diferença ( $p>0,05)$ entre as formulações para contagens de cocos láticos Gram positivos $(9,03$ a $9,45 \log U F C / g)$ e lactobacilos (8,31 a 9,19 log UFC/g). O tempo de armazenamento interferiu na contagem ( $\mathrm{p}<0,05)$ de cocos (nos tempos: 7 e 14) e contagens de lactobacilos que variaram de 8,49 a $9,27 \log$ UFC/g para formulação controle (sem adição de FBV) e 8,5 a $8,7 \log$ UFC/g ao longo de 28 dias de armazenamento para formulação com adição de FBV. A concentração de FBV não foi suficiente para apresentar efeito prebiótico, visto a viabilidade das bactérias láticas não apresentar diferença significativa.

Nogueira et al. (2016) - Artigo ID19 - desenvolveram bebidas de kefir com leite integral e polpa de açaí, utilizando duas culturas diferentes de kefir, uma original de leite e outra de água açucarada adaptada (formulações: 70/30 e 30/70 (g.g ${ }^{-1}$ ) leite integral e polpa de açaí, respectivamente, avaliados T0 e T24 h). O aumento da concentração de polpa de açaí resultou na diminuição do valor de $\mathrm{pH}$ inicial nas formulações; ao final houve redução nos valores de $\mathrm{pH}$ menos acentuada para a cultura de kefir adaptada. Os valores de sólidos solúveis apresentaram diferença $(\mathrm{p}<0,05)$ entre as formulações após 24 h. A análise sensorial revelou que todas as formulações apresentaram valores médios dos atributos (faixa aceitável; acima de 5.0). Concluindo que a utilização da cultura adaptada, apresentou melhores resultados, (água açucarada) (formulação: 70 de leite, $30 \%$ de polpa de açaí, temperatura ambiente $\sim 25^{\circ} \mathrm{C} / 24 \mathrm{~h}$ sem agitação) apresentou pH 5,1 e aceitação global de 7,05.

Puerari, Magalhães e Schwan (2012) - Artigo ID20 - elaboraram bebidas fermentadas de kefir a base de cacau (condições de temperatura e tempo entre $10{ }^{\circ} \mathrm{C}$ e $25{ }^{\circ} \mathrm{C}$ durante 48 e $72 \mathrm{~h}$ ), observaram por meio das análises microbiológicas que não houve diferença entre as bebidas fermentadas e os grãos de kefir. $\mathrm{O}$ valor de $\mathrm{pH}$ apresentou redução, principalmente nas primeiras 48 horas, registrando 3,8 no final da fermentação. As bebidas fermentadas a $10{ }^{\circ} \mathrm{C}$ durante $48 \mathrm{~h}$ e $72 \mathrm{~h}$, obtiveram a maior aceitação ( $92 \%$ e $100 \%$ do painel, respectivamente) com base no sabor, odor e aparência, além de um baixo teor alcoólico e acidez. Além disso, este estudo desenvolveu bebidas alcoólicas de kefir (concentração de etanol de $\sim 45,0 \mathrm{~g} \mathrm{~L}$ - $1(3,6 \% \mathrm{v} / \mathrm{v})$ com a polpa de cacau por um período de 48 e $72 \mathrm{~h}$ a $25^{\circ} \mathrm{C}$, com $80 \%$ de aceitação dos avaliadores.

Sousa et al. (2021) - Artigo ID21 - elaboraram queijo petit-suisse de kefir com sabor de goiaba, e inulina em concentrações variáveis nas formulações (inulina/açúcar $0 \% / 14 \%, 3 \% / 11 \%$ e $6 \% / 8 \%$, respectivamente). Os achados deste estudo mostraram que a adição de inulina alterou significativamente as características físico-químicas e centesimais com exceção para os parâmetros de umidade, atividade de água, cinzas, proteínas e carboidratos. As características sensoriais mostraram que a inulina interferiu nos parâmetros de sabor, impressão global e intenção de compra, em detrimento da aparência, aroma e textura. As formulações apresentaram Índice de Aceitabilidade superior a 70\% para a maioria dos atributos sensoriais no tempo final de armazenamento. Além disso, as formulações com e sem inulina apresentaram qualidade microbiológica estando em conformidade com a legislação. Não obstante, ao final do tempo de armazenamento houve redução na contagem de BAL, bactérias acéticas e leveduras. Configurando em um produto com características sensoriais e microbiológicas estáveis (28 dias).

Santos et al., (2012) - Artigo ID22 - estudaram queijo petit suisse de kefir nos sabores morango, mangaba, ervas e tomate seco, os aspectos sensoriais revelaram frequências acima do termo "Indiferente" (5), na escala hedônica de 9 pontos, 
para aceitação geral, aparência e sabor, as formulações receberam avaliações superior cinco em todos os testes, no que se refere a intenção de compra, a maioria compraria as formulações doces pelas alegações de saúde, as amostras salgadas forma classificadas acima das amostras doces $(\mathrm{p}<0,05)$, com as maiores pontuações acima do termo "Indiferente". Assim, os resultados apontam que, em termos gerais, as formulações apresentaram boa aceitação pelos avaliadores.

Diversas variáveis podem ser determinantes nas características dos produtos à base de kefir, como proporção de grãos de kefir utilizados, a falta de padronização das culturas de grãos de kefir, tipo de substrato, adição de fibras, concentração das frutas em forma de polpa, farinha, entre outros, portanto, sugere-se o desenvolvimento de estudos utilizando culturas iniciais para verificar se há uma padronização desses parâmetros (Alves, Cunha \& Valente, 2019).

A análise sensorial pode sofrer interferência de diversos fatores, como preferências, experiências, idade, sexo, expectativa, condição socioeconômica, dentre outros fatores, bem como, a intenção de compra, que por sua vez, está relacionada a aspectos como preço, design, indicação, benefícios à saúde, a partir do consumo, vir influenciar (Ricarte et al., 2019). O fato dos avaliadores não serem treinados, o tamanho da amostra destes, descrita nos estudos, pode não ser expressiva para oferecer dados confiáveis, assim como, as características peculiares das frutas e do kefir, cujos avaliadores não estejam familiarizados, dentre outros ingredientes utilizados (como o açúcar de coco e mel) por não serem ainda amplamente disseminados no mercado de produtos alimentícios, consequentemente, interferir na aceitação.

Diversos fatores podem influenciar e definir os aspectos físico-químicos, instrumentais, microbiológicos e nutricionais do produto obtido a partir de grãos de kefir; proporção de grãos para o substrato, temperatura e tempo de fermentação, resfriamento, amadurecimento, condições de armazenamento, substrato utilizado, dentre outros (Araújo et al., 2017). Esses fatores foram evidenciados nos estudos selecionados, por intervirem em uma parcela destes, há uma necessidade de pesquisas, na qual, a única variável na formulação seja a proporção e a forma de processamento das frutas que são adicionadas ao produto, entretanto, não foram observados na literatura estudos que utilizem culturas iniciais.

Como limitações observa-se que poucos estudos abordam a inserção ou não dessas frutas nas formulações e sua interferência na caracterização dos produtos, sendo necessário o desenvolvimento de mais pesquisas que abordem especificamente essa relação. Poucos estudos caracterizaram a qualidade microbiológica dos produtos no que concerne a microrganismos patogênicos, sugerindo-se a necessidade de mais trabalhos que respaldem a segurança do consumo de produtos obtidos a partir do kefir. A caracterização físico-química apresentou divergência entre os estudos, porém, para alguns produtos inovadores não há subsídios suficientes para classificar a adequação.

Em contrapartida, as percepções sensoriais foram conclusivas nos estudos realizados e fornecem informações que norteiam uma possível boa aceitação e intenção de compra destes produtos pelo mercado consumidor, embora, apenas quatro estudos apresentem índice de aceitabilidade superior a 70\% (IDI; ID6; ID20 e ID21), e que, portanto, são considerados sensorialmente bem aceitos (Teixeira, 2009).

As características nutricionais, viabilidade microbiana, presença de compostos fenólicos e antioxidantes, agregam valor comercial a esses produtos. Não obstante, a elevação da acidez titulável e redução do pH demonstrados nesses produtos são característicos de alimentos fermentados de kefir.

A investigação de vida útil, assim como a busca de formas de aplicação das frutas que visem uma maior estabilidade são necessárias, visto que, poucos estudos analisaram os produtos desenvolvidos durante diferentes tempos de armazenamento. Além disso, poucos estudos evidenciam a composição de micronutrientes dos produtos, ressaltando que essas características agregam qualidade nutricional e despertam o interesse por parte do mercado consumidor e consequentemente da indústria.

\section{Considerações Finais}

Com base nos resultados obtidos nessa revisão, os produtos desenvolvidos com kefir e frutas do semiárido brasileiro 
apresentaram-se como boas alternativas para o consumo, tendo em vista, as características sensoriais, nutricionais e funcionais destes produtos, especialmente, os efeitos probióticos evidenciados em todos os estudos que fizeram a determinação de bactérias ácido láticas. Ressalta-se que a comercialização destes produtos viabilizaria o consumo de alimentos com maior segurança microbiológica e estabilidade. Deve-se considerar que a cultura obtida de forma artesanal e/ou manipulada em ambiente doméstico, sem passar por um controle rigoroso de qualidade aliado a procedimentos higiênico-sanitários inadequados, pode favorecer a contaminação dos grãos, como observado em dois estudos incluídos na revisão constatada como impróprios para o consumo.

A agregação de frutas do semiárido brasileiro nesses produtos fermentados ainda é recente e progressiva, dessa forma, o quantitativo de estudos não traz subsídios suficientes para constatação do potencial mercadológico desses produtos, mas evidenciam que sua aplicação está em expansão e mediante a análise realizada, esse potencial pode ainda ser mais explorado como alternativa promissora no mercado de alimentos potencialmente funcionais. Portanto, sugere-se que informações como estabilidade e vida útil sejam fornecidas em pesquisas futuras, visto que essas características foram abordadas em uma quantidade reduzida de estudos.

Sugere-se ainda, que novos produtos sejam desenvolvidos com frutas adicionadas como ingredientes no produto fermentado de kefir de leite, assim como a utilização de outras frutas como substratos para fermentação de kefir de água açucarado, pois, a maior parte das aplicações foi em forma de polpa. Considerar ainda, os diferentes processamentos que trazem uma vasta informação quanto aos aspectos sensoriais, assim como, verificar se os aspectos nutricionais da fruta são preservados após o processamento.

\section{Agradecimentos}

Os autores agradecem ao Instituto Federal de Educação, Ciência e Tecnologia do Ceará (IFCE) e a Coordenação de Aperfeiçoamento de Pessoal de Nível Superior (CAPES) pela concessão de bolsas de estudo.

\section{Referências}

Akonor, P. T. (2020). Optimization of a fruit juice cocktail containing soursop, pineapple, orange, and mango using mixture design. Scientific African, 8(1), 00368. https://doi.org/10.1016/j.sciaf.2020.e00368

Alves, R. G., Lelis, V. G., Cunha, A. F., \& Valente, F. X. (2019). Avaliação físico-química do leite fermentado de kefir produzido de maneira artesanal em viçosa. Revista Científica Univiçosa, 10(1), 1185- 1190.

Alves, V., Scapini, T., Camargo, A. F., Bonatto, C., Stefanski, F. S., Jesus, E. P., Diniz, L. G. T., Bertan, L. C., Maldonato, R. R., \& Treichel, H. (2021). Development of fermented beverage with water kefir in water-soluble coconut extract (Cocos nucifera L.) with inulin addition. LWT- Food Science and Technology, 145(1), 111364. DOI: https://doi.org/10.1016/j.lwt.2021.111364

Amorim, A. M., Lelis, V. G., \& Costa, Y. A. (2018). Elaboração e análise sensorial de uma bebida com propriedades antioxidantes à base de chá verde, gengibre, hortelã e abacaxi. Revista Científica UniScientiae, 1(1), 1-12.

Araújo, M. F., Peixoto, S. G. A. S., Braga, D., Oliveira, M. S. L. P., Duarte, S. M., Rocha, F. G. S., \& Farias, P. K. S. (2019). Kefir de água e leite: composição físico-química em diferentes substratos. RBONE-Revista Brasileira de Obesidade, Nutrição e Emagrecimento,13(80), 645-651.

Araújo, N. G., Silva, J. B., Barbosa, I. M., \& Macêdo, C. S. (2017). Influência da concentração de polpa de goiaba na aceitação de fermentado de kefir. Revista do Instituto de Laticínios Cândido Tostes, 72(4), 184-191. DOI: https://doi.org/10.14295/2238-6416.v72i4.552

Bourrie, B. C. T., Cotter, P. D., \& Willing, B. P. (2018). Traditional kefir reduces weight gain and improves plasma and liver lipid profiles more successfully than a commercial equivalent in a mouse model of obesity. Journal of Functional Foods, 46(1), 29-37. https://doi.org/10.1016/j.jff.2018.04.039

Brandão, T. V., Cintra, A. C., Souza, P. R., Oliveira, E. F., Oliveira, N., Ciarelli, G., Souto, R. N. M., \& Dolinsky, M. (2020). Concentração de polifenóis no abacaxi pérola, banana prata, mamão Papaya e melancia orgânicos e convencionais. Brazilian Journal of Health Review, 3(5), 15092-15108. https://doi.org/10.34119/bjhrv3n5-293

Brasil (2007). Ministério da Agricultura, Pecuária e Abastecimento. Instrução Normativa n 46, 23 de outubro de 2007. Aprova o Regulamento Técnico de Identidade e Qualidade de Leites Fermentados. Diário Oficial da República Federativa do Brasil, Brasília, DF, Seção 1, p. 5.

Brasil. (2002). Ministério da Saúde. Secretaria de Políticas de Saúde. Coordenação-Geral da Política de Alimentação e Nutrição. Alimentos regionais brasileiros. Brasília: Ministério da Saúde. 84 p. 
Brasil. (2015). Ministério da Saúde. Secretaria de Atenção à Saúde. Departamento de Atenção Básica. Alimentos regionais brasileiros. 2. ed. Brasília: Ministério da Saúde. 484 p.

Cavararo, C. S., Silva Junior, J. P., Domingues, J. R., \& Chiappini, C. C. J. (2018). Desenvolvimento e aceitação sensorial de kefir com geleia de goiaba e avaliação de compostos bioativos. DEMETRA: Alimentação, Nutrição \& Saúde, 13(2), 503-515.

Contim, L. S. R., Oliveira, I. M. A., \& Cardoso Neto, J (2018). Avaliação microbiológica, físico-química e aceitação sensorial do kefir com polpa de graviola. Revista do Instituto de Laticínios Cândido Tostes, 73(1), 1-9. https://doi.org/10.14295/2238-6416.v73i1.604

Destro, T. M., Prates, D. D. F., Watanabe, L. S., Garcia, S., Biz, G., \& Spinosa, W. A. (2019). Organic brown sugar and jaboticaba pulp influence on water kefir fermentation. Ciência e Agrotecnologia, 43(1), 1-17. https://doi.org/10.1590/1413-7054201943005619

Dias, W. C., Martins, A. D. O., \& Moreira Júnior, S. (2020). Kefir: características e benefícios. Alimentos: Ciência, Tecnologia e Meio Ambiente, 1(7), 22-42.

Dyba, T., \& Dingsoyr, T. (2008). Empirical Studies of Agile Software Development: A Systematic Review. Information and Software Technology, 50(9-10), 833-859. https://dx.doi.org/10.1016/j.infsof.2008.01.006

Donato, H., \& Donato, M. (2019). Etapas na condução de uma Revisão Sistemática. Acta Médica Portuguesa, 32(3) 227-235. https://doi.org/10.20344/amp.11923

Dutcosky, S. D. (2013). Análise sensorial de alimentos. (4a ed.), Champagnat, 531 p.

Ferreira, J. V., Schirmann, G. S., Santos, M. L. P., Zago, A. C., De Souza Bortolini, V. M. S., Rockenbach, R., \& Bragança, G. C. M. (2020). Parâmetros físico-químicos e aceitabilidade de sorvetes desenvolvidos a partir de diferentes leites fermentados por kefir, jabuticaba (Myrciaria cauliflora (Mart.) O. Berg) e mel de abelha silvestre. Brazilian Journal of Development, 6(11), 85434-85451. https://doi.org/10.34117/bjdv6n11-094

Ferreira, Z. R., \& Vieira Filho, J. E. R. (2021). Irrigação pública e fruticultura no Semiárido. Revista de Política Agrícola, 1(1), 34-50.

Gomes, F. O., Silva, M. D. C. M., Sousa, P. B., Freitas, T. K. T., Silva, D. J. S., \& Araújo, R. S. D. R. M. (2020). Avaliação físico-química de uma bebida à base de kefir saborizada com pequi. Brazilian Journal of Development, 6(3), 10755-10762. https://doi.org/10.34117/bjdv6n3-084

Gonçalves, F. I., Martins, E. M F., Silva, V. R. O., \& Martins, A. D. O. (2018). Efeito de yacon na aceitação sensorial de kefir e viabilidade de bactérias láticas na bebida. Revista Vértices, 20(2), 194-201. https://doi.org/0.19180/1809-2667.v20n22018p194-201

Januário, J. G. B., Oliveira, A. S., Dias, S. S., Klososki, S. J., \& Pimentel, T. C. (2018). Kefir ice cream flavored with fruits and sweetened with honey: physical and chemical characteristics and acceptance. International Food Research Journal, 25(1), 179-187.

Lima, N. M. F., Holanda, C. A., Cruz, G. A., Sales, L. G. M., Bruno, L. M., \& Carvalho, J. D. G (2020). Development of kefir from goat milk with guava pulp. Research, Society and Development, 9(7), 0468973943. http://dx.doi.org/10.33448/rsd-v9i7.3943

Magalhães-Guedes, K. T., Barreto, I. T., Tavares, P. P. L. G., Bezerra, P. Q. M., Silva, M. R., Nunes, I. L., Mamede, M. E. O., Miguel, M. G. C. P., \& Schwan, R. F. (2020). Effect of kefir biomass on nutritional, microbiological, and sensory properties of mango-based popsicles. International Food Research Journal, 27(3), 536-545.

Microsoft Corporation. (2013). Microsoft Office Excel. 13.0. Microsoft Corporation. CD-ROM.

Miranda, E. S. M., Oliveira, V. M. S., Braga, R. C., \& Damaceno, M. N. (2021). Avaliação de cor e textura de pão de forma integral com grãos de fabricação industrial e artesanal. Revista Brasileira de Agrotecnologia,11(2), 322-327. https://doi.org/10.18378/REBAGRO.V12I2.8782

Moreira Junior, S. M., Rodrigues, M. P. J., Benevenuto, W. C. A. N., \& Martins, A. D. O. (2018). Efeito da farinha de banana verde no crescimento de bactérias láticas contidas nos grãos de kefir. Revista Higiene Alimentar, 32(282-283), 70-74.

Nogueira, L. K., Aguiar-Oliveira, E., Kamimura, E. S., \& Maldonado, R. R. (2016). Milk and açaí berry pulp improve sensorial acceptability of kefirfermented milk beverage. Acta Amazônica, 46(1), p. 417-424.

Parreiras, P. M., Dantas, M. I. S., Coelho, A. I. M., \& Souza, E. C. G. (2019). Desenvolvimento de sorvete de kefir com polpa de manga: Avaliação sensorial, físico-química e de bactérias ácido láticas. Semina: Ciências Biológicas e da Saúde, 40(1), 109-118. https://doi.org/10.5433/1679-0367.2019v40n1p109

Pattaro, L., Silva, J. A. G., Farias, L. C. B., Medeiros, J. S., Teixeira, P. C., Cunha, J. V. T., More, J. C. R. S., Almeida, T. V., Nicolau, E. S., \& Silva, M. A. P. (2020). Análises físico-químicas e sensoriais de smoothies do leite de diferentes espécies fermentado por kefir, saborizados com banana e maçã. Research, Society and Development, 9(5), 1-18. https://doi.org/10.33448/rsd-v9i5.3145

Pinheiro, P. S., Gonçalves, P. S., Martins, A. D. O., Alves, L. A. B., Silva, R. R., Nogueira, C. H., \& Dias, W. C. (2020). Viabilidade de bactéria lática em frozen adicionado de kefir. Alimentos: Ciência, Tecnologia e Meio Ambiente, 1(6), 1-10.

Pletsch, L. B. H., Severo, J., Hermanns, G., \& Preichardt, L. D. (2019). Gelado comestível de kefir adicionado de polpa de jabuticaba e morango. Revista Instituto de Laticínios Cândido Tostes, 74 (1), 39-50. https://doi.org/10.14295/2238-6416.v74i1.701

Puerari, C., Magalhães, K. T., \& Schwan, R. F. (2012). New cocoa pulp-based kefir beverages: Microbiological, chemical composition and sensory analysis. Food Research International, 48(2), 634-640. https://doi:10.1016/j.foodres.2012.06.005

Ricarte, D., Almeida Júlio, B. L., Zocateli, G. A. F., Barreto, R. L. F., Guimarães, M., Ferreira, R. S., \& Guimarães, N. S. (2019). Análise sensorial de preparações com batata yacon: revisão sistemática. HU Revista, 45(4), 431-440. https://doi.org/10.34019/1982-8047.2019.v45.28419

Sales, L. G. M., Cruz, G. A., Bruno, L. M., Lima, N. M. F., Machado, F. L. O., \& Carvalho, J. D. G. (2020). Caracterização e estabilidade de kefir com adição de polpa de açaí. Research, Society and Development, 9(8), 293985189. https://doi.org/10.33448/rsd-v9i8.5189 
Research, Society and Development, v. 10, n. 13, e349101321079, 2021

(CC BY 4.0) | ISSN 2525-3409 | DOI: http://dx.doi.org/10.33448/rsd-v10i13.21079

Sampaio, R. F., \& Mancini, M. C. (2007). Estudos de revisão sistemática: um guia para síntese criteriosa da evidência científica. Brazilian Journal of Physical Therapy, 11(1), 83-89. https://doi.org/10.1590/S1413-35552007000100013

Santos, D. C., Oliveira Filho, J. G., Santana, A. C. A., Freitas, B. S. M., Silva, F. G., Takeuchi, K. P., \& Egea, M. B. (2019). Optimization of soymilk fermentation with kefir and the addition of inulin: Physicochemical, sensory and technological characteristics. Food Science and Technology, 104(1), 30-37. https://doi.org/10.1016/j.lwt.2019.01.030

Santos, T. S. S., Martins, J. D. F. L., Rocha, D. M. U. P., \& Moreira, A. V. B. (2012). "Petit suisse" cheese from kefir: an alternative dessert with microorganisms of probiotic activity. Food Science and Technology, 32(1), 485-491. https://doi.org/10.1590/S0101-20612012005000077

Silva, A. S., \& Pedro, M. A. M. (2018). Estudo da influência da desidratação osmótica na secagem de fatias de abacaxi. Revista Científica, 1(1), 1-11.

Silva, C. F. G., Santos, F. L., Santana, L. R. R., Silva, M. V. L., \& Conceição, T. A. (2018). Development and characterization of a soymilk Kefir-based functional beverage. Food Science and Technology, 38(3), 543-550. https://doi.org/10.1590/1678-457x.10617

Silva, M. V., Nascimento, E. C. D. S., Ferreira, E. C. N., \& Galúcio, V. C. A. (2020). Análise de crescimento do kefir em polpa de açaí. Saber Científico, 9(2), 1-10. https://dx.doi.org/10.22614/resc-v9-n2-1297

Silva, M. S. B., \& Okura, M. H. (2021). Produtos à base de Kefir desenvolvidos e estudados no Brasil. Research, Society and Development, 10(7), 19010716491. http://dx.doi.org/10.33448/rsd-v10i7.16491

Sousa, P. B., Guimarães, T. L. F., Silva, P. L., Miranda, E. S. M., Castro, E. A., Monção, É. C., Santos, S. M. L., Mendes, L. G., Cavalcante, A. B. D., \& Damaceno, M. N. (2021). Effect of inulin addition on the physicochemical, microbiological, and sensory characteristics from guava-flavored petit-suisse kefir cheese. Research, Society and Development, 10(8), e7010817139. https://doi.org/10.33448/rsd-v10i8.17139

Souza, H. G. D., Tabosa, F. J. S., Campos, K. C., Vieira Filho, J. E. R., \& Neder, H. D. (2018). Análise da projeção espacial da fruticultura no Nordeste brasileiro. Revista Econômica do Nordeste, 49(4), 121-141.

Tavares, P. P. L. G., Dos Anjos, E. A., Nascimento, R. Q., Da Cruz, L. F. S., Lemos, P. V. F., Druzian, J. I., Oliveira, T. T. B., Andrade, R. B., Sousa, A. L. C., Magalhães-Guedes, K. T., \& Mamede, M. E. O. (2021). Chemical, microbiological and sensory viability of low-calorie, dairy-free kefir beverages from tropical mixed fruit juices. CyTA-Journal of Food, 19, (1), 457-464. https://doi.org/10.1080/19476337.2021.1906753

Teixeira L. V. (2009). Análise sensorial na indústria de alimentos. Revista Instituto de Laticínios Cândido Tostes. 64 (366), 12-21.

Tomar, O., Akarca, G., Çağlar, A., Beykaya, M., \& Gök, V. (2020). The effects of kefir grain and starter culture on kefir produced from cow and buffalo milk during storage periods. Food Science and Technology, 40(1), 238-244. https://doi.org/10.1590/fst.39418 